\title{
LA TENDENCIA AL DELITO COMO REQUISITO MATERIAL PARA LA APLICACIÓN DE MEDIDAS DE SEGURIDAD A SUJETOS IMPUTABLES
}

\author{
Viviana CARUSO FonTÁN \\ Profesora Contratada Doctora \\ Universidad Pablo de Olavide de Sevilla \\ vcaruso@upo.es
}

\begin{abstract}
RESUMEN
Con la reforma operada al Código Penal en el año 2010 el legislador se aleja del modelo elegido en el año 1995 y propone la aplicación de medidas de seguridad para el tratamiento del delincuente plenamente responsable, opción que se intensifica en el proyecto de reforma, actualmente en tramitación. Este trabajo propone una revisión bistórica y conceptual de la tendencia al delito, concebida como uno de los principales requisitos para la aplicación de las medidas de seguridad aplicables al delincuente imputable.
\end{abstract}

Palabras clave: penas, medidas de seguridad, custodia de seguridad, tendencia, delincuente habitual, prevención especial.

\section{ABSTRACT}

With the new wording of the Spanish Penal Code of 2010 legislators stay away from the pattern chosen in 1995 and offer the safety measures implementation on a fully responsible criminal, which is a choice even more clearly established in the reform project, currently in progress. This piece of work offers a historic and conceptual review of crime inclination understood as one of the main requirements of safety measure implementation applicable to the imputable criminal.

Keywords: sentences, safety measures, prison guard, trend, usual criminal, special prevention.

\section{ZUSAMMENFASSUNG}

Mit der Reform des Spanischen Strafgesetzbuchs im Jahr 2010 bat der Gesetzgeber sich vom gewäblten Strafmodell aus dem Jahr 1995 entfernt und favorisiert nun die Anwendung von Sicherheitsmaßnahmen gegenüber Straftätern, die voll strafverantwortlich sind. Dies ist eine Entscheidung, die sich im Reformprojekt ver-

* El presente trabajo ha sido elaborado en el marco del proyecto de investigación «Análisis crítico de la reforma de 2010 del Código Penal: con especial referencia a las incorporaciones en la Parte General y nuevas figuras delictivas», DER 2011-27473 MECC. 
stärkt, das sich derzeit in der Ausarbeitungsphase befindet. Der Aufsatz nimmt eine historische und konzeptionelle Überprüfung der Straftatneigung vor, die als grundlegende Voraussetzung zur Anwendung der Sicherheitsverwabrung gegenüber dem Straftäter gilt.

Schlüsselwörter: Strafen, Sicherheitsmaßnahmen, Sicherheitsverwahrung, Straftatneigung, Gewohnheitstäter, spezielle Vorbeugung.

SUMARIO: I. INTRODUCCIÓN.-II. LAS MEDIDAS DE SEGURIDAD APLICABLES AL DELINCUENTE PELIGRO. ORIGEN DE LA FIGURA.-1. Las medidas de seguridad como solución de compromiso.-2. Las medidas de seguridad en la época nacionalsocialista.-3. Las medidas de seguridad durante la época de posguerra.-III. TENDENCIA Y PELIGROSIDAD. LOS REQUISITOS MATERIALES DE LA MEDIDA DE CUSTODIA DE SEGURIDAD.IV. ¿TIENE CABIDA EL CONCEPTO DE DELINCUENTE POR TENDENCIA EN EL DERECHO ESPAÑOL?

\section{INTRODUCCIÓN}

El tratamiento de la delincuencia habitual es un tema que ha ocupado, y sigue ocupando hoy en día, tanto a gobernantes como a estudiosos del Derecho. Se trata de una materia especialmente sensible, en cuanto implica pronunciarse sobre una disyuntiva difícil de resolver: el conflicto entre la pretensión de seguridad que esgrime la sociedad en su conjunto y las garantías individuales del sujeto supuestamente peligroso. Para abordar esta problemática suelen tomarse dos caminos: o bien recurrir a la exacerbación de la pena a través de la aplicación de agravantes que castiguen la reiteración de hechos delictivos, o hacer uso de medidas que encuentren su fundamentación en la peligrosidad criminal. Hasta la reforma operada al Código Penal en 2010, España había tomado partido, de forma decidida, por la primera opción; no obstante, esta decisión político-criminal ha iniciado un nuevo rumbo con la incorporación a nuestro Derecho de la medida de libertad vigilada y con la apertura del debate sobre la posible introducción de la custodia de seguridad. Con ello es posible sostener que el legislador español está cediendo a la incorporación de instituciones que nos resultan ajenas y que podrían ser consideradas como ejemplos de un modelo de Derecho penal autoritario.

En este sentido, resulta destacable el hecho de que uno de los requisitos materiales sobre los que se asienta la institución de la custodia de seguridad en el Código Penal alemán es la «tendencia» al delito, exigencia a la que también se sumará la peligrosidad criminal del autor. A simple vista 
pueden observarse las dificultades que se derivan de la interpretación de conceptos tan sumamente abstractos e indeterminados. Para afrontar esta tarea y poder conocer el alcance que puede darse a estos términos consideramos imprescindible analizar el origen y desarrollo de los mencionados conceptos. Creemos que este estudio puede ser de suma utilidad para obtener conclusiones sobre la naturaleza y admisibilidad de las medidas de seguridad aplicables a la delincuencia habitual.

\section{LAS MEDIDAS DE SEGURIDAD APLICABLES AL DELINCUENTE PELIGROSO. ORIGEN DE LA FIGURA}

\section{Las medidas de seguridad como solución de compromiso}

Para conocer el momento en que se introduce el concepto de peligrosidad en las teorías penales debemos retrotraernos a la lucha de escuelas que tiene lugar a finales del siglo XIX. Tendremos que centrarnos, por tanto, en el enfrentamiento que tuvo lugar entre la llamada escuela clásica y el movimiento positivista italiano encabezado por Cesare Lombroso.

La denominación «escuela clásica» fue utilizada por primera vez por Enrico Ferri para referirse a un grupo de teorías que no comulgaban con sus ideas positivistas. El autor pretendía asignarle a esta expresión un significado peyorativo, haciendo alusión a ideas viejas o vetustas, significado que, sin embargo, no necesariamente tiene la expresión «clasicismo», que también puede ser entendida como «lo consagrado» o «lo ilustre» ${ }^{1}$. De esta forma quedaron agrupadas una serie de teorías cuyo principal denominador común fue el enfrentamiento que mantenían con la postura revolucionaria defendida por Lombroso y sus discípulos. Puede sostenerse, sin lugar a dudas, que la escuela clásica fue heredera del movimiento de la Ilustración. Se trataba de dar continuidad a la tarea iniciada por autores de la talla de Beccaria o Bentham, quienes habían luchado firmemente en contra de la crueldad del Antiguo Régimen ${ }^{2}$. Fueron momentos de revolución los que pusieron en evidencia la necesidad de un nuevo orden capaz de crear un sistema que sirviera de escudo y lograra proteger al pueblo frente al terror del poder absoluto. Una hazaña de esta magnitud sólo

${ }^{1}$ L. Jiménez de Asúa, Principios de Derecho Penal. La Ley y el Delito, Buenos Aires, Abeledo Perrot, 1990, p. 45.

2 L. JiménEZ DE AsúA, La utopía penal de Dorado Montero, Salamanca, 1959, p. 40. También véase J. Frías Caballero, Temas de Derecho penal, Buenos Aires, La Ley, 1970, p. 11. 
podría conseguirse a través del establecimiento de unos férreos principios con vocación universal, donde la defensa de los derechos del individuo se situara en un indiscutible primer plano.

La escuela clásica quiso continuar esta tarea tomando un camino diferente al de sus predecesores. Así, mientras en los años de la Revolución primaba la defensa de los postulados de la prevención general negativa ${ }^{3}$, la

3 Durante el Antiguo Régimen a través de la aplicación de penas infamantes se pretendía principalmente conseguir un efecto de intimidación sobre el pueblo. Posteriormente, los autores de la época de la Ilustración combatieron la crueldad de los castigos, pero mantuvieron la necesidad de satisfacer, a través de la imposición de la pena, los fines de la prevención general negativa. Fue el caso del marqués de Beccaria, quien sostuvo: «¿Queréis evitar los delitos? Haced que las leyes sean claras y simples, y que toda la fuerza de la Nación esté empleadas en defenderlas, ninguna parte en destruirlas [...] Haced que los hombres las teman, y que no teman más que a ellas. El temor de las leyes es saludable, pero el del hombre a hombre es fatal y fecundo de delitos». No obstante, puede observarse que el marqués de Beccaria en su obra también defiende postulados de prevención especial. Así se pone de manifiesto cuando expresa: «El fin, pues, no es otro que impedir al reo causar nuevos daños a sus ciudadanos y retraher los demás de la comisión de otros iguales. Luego deberán ser escogidas aquellas penas, y aquel método de imponerlas, que guardada la proporción, hagan una impresión más eficaz y más durable sobre los ánimos de los hombres, y la menos dolorosa sobre el cuerpo del reo». Cfr. C. Marqués de BeCCARIA, Tratado de los delitos y la penas, trad. de J. A. de las Casas, Madrid, Joachin Ibarra, 1774, p. 232. También Jeremy Bentham consideraba a la prevención general negativa como el objeto principal de las penas. En su opinión, si se viera al delito como un hecho aislado, que no puede volver a ocurrir, la pena se convertiría en algo inútil porque sólo serviría para agregar un mal a otro, pero si se entendiese que un delito no castigado abre la puerta no sólo al delincuente, sino a todos los que tuviesen los mismos motivos y ocasiones para cometerle, la pena que se aplica al individuo cumpliría una función de salvaguarda universal. Así considerada, la pena se eleva a la primera clase de servicios públicos, ya que se la mira no como un acto de ira o venganza contra un criminal o un desgraciado que cede frente a inclinaciones funestas, sino como un sacrificio indispensable para la seguridad nacional. Cfr. J. Bentham, Teoría de las penas y de las recompensas, obra sacada de los manuscritos por Esteban Dumont y traducida al español de la 3. ${ }^{a}$ ed. publicada en Francia por DLB, Barcelona, 1838, p. 15. Para Bentham resultaba, por tanto, indispensable que la pena se ejecutara de manera pública para su mayor difusión y eficacia. Por ello diferenciaba el «valor aparente» y el «valor real» de las penas. El primero se refería al mal que se representaría en la imaginación de la población por la descripción o la vista de la ejecución de la pena y el segundo hacía alusión al mal que sufriría el condenado por la imposición de la pena. De acuerdo con ello, Bentham entendía que era necesario rodear a la ejecución de la pena de todas las solemnidades necesarias para que la gravedad de la misma fuera trasladada a la mente de los asistentes, sin que en realidad fuera tanta como se aparentaba. Por ello, la ejecución de la pena era, a su modo de ver, un verdadero arte, que consistía en aumentar la pena aparente sin aumentar la pena real. Consecuentemente, afirmaba Bentham: «Todo individuo se gobierna, aun sin saberlo, por un cálculo bien o mal hecho de pena o de placeres. ¿Juzga con anticipación que la pena será la consecuencia de una acción que le gusta? Esta idea tiene sobre él cierta fuerza para que no la cometa. ¿El valor total de la pena le parece mucho mayor que el del placer? La fuerza repulsiva será la mayor y no se verificará la acción». Cfr. J. BENTHAM, Tratados de Legislación Civil y Penal, t. IV, traducidos y comentados por B. Arduaga Espinosa, Madrid, Oficina del Establecimiento Central, 1842, p. 46. 
escuela clásica propició la implantación de un sistema retributivo ${ }^{4}$. Sus postulados partían de la idea de libre albedrío. Se consideraba que el hombre es libre de tomar sus propias decisiones, por lo que, si decide delinquir habiendo podido actuar de otro modo, se hace indefectiblemente merecedor de un reproche ${ }^{5}$. Estas ideas, que a simple vista podían revelar un exceso en el rigor punitivo, también podían ser entendidas como una verdadera arma de defensa del individuo frente al poder estatal. Así, a pesar de que en esta concepción la pena será considerada como un castigo, también es cierto que estas penas deberán ser necesariamente determinadas y proporcionales a la gravedad del hecho y la culpabilidad del autor. Puede deducirse, por tanto, que la pena retributiva funcionaba como una garantía para el individuo frente a los excesos del poder punitivo. La teoría clásica lograba, de esta manera, erigir al Derecho penal como baluarte de las libertades individuales, las cuales se fortalecían, a su vez, con una rígida estructuración de las distintas categorías que configuraban la estructura del delito ${ }^{6}$.

${ }^{4}$ Así, a pesar de que en la época de la Ilustración dominó una concepción utilitarista, la escuela clásica destaca de estos planteamientos, especialmente, la exigencia de la legalidad y la humanización de los castigos, eso es, lo que podría denominarse su «liberalismo penal». Cfr. J. Antón Oneca, Obras, t. I, Buenos Aires, Rubinzal Culzoni, 2000, p. 155.

5 Sobre este extremo, L. JimÉnez de AsúA, Principios de Derecho Penal..., op. cit., p. 46. En el caso de Kant, la necesidad absoluta de la pena se deriva de un mandato incondicional de la justicia que no admite valoraciones y excepciones. La pena debe imponerse cada vez que se cometa un delito y no hacerlo supone un fracaso. La ley penal es un imperativo categórico y la pena debe imponerse sólo porque se ha delinquido, aun cundo ésta resulte innecesaria para el bien de la sociedad. De acuerdo con esta concepción, la aplicación de una pena no puede responder a ningún otro objetivo que no sea la realización de la justicia o el mantenimiento del Derecho. La imposición de una pena para satisfacer fines preventivos podría implicar la negación de la dignidad del hombre en cuanto supone su utilización para la satisfacción de fines de utilidad social. Cfr. I. KANT, La metafísica de las costumbres, traducción y notas de A. Cortina y J. Canal Sancho, Madrid, Tecnos, 1989, p. 168. En el caso de Hegel, el carácter retributivo de la pena se justifica por la necesidad de restablecer la vigencia de la voluntad general representada por el orden jurídico y que resulta negada por la voluntad especial del delincuente. Así, la pena es una especie de retorsión de la propia negación del Derecho que el delincuente intentara; una voluntad racional, al querer la violación del Derecho, es como si quisiera la pena. Así vista, la pena aparece como la negación de la pretendida negación del Derecho; es la demostración de su irrealidad y, con ello, el restablecimiento del imperio inatacable del Derecho. De ahí su necesidad absoluta. Al respecto S. Soler, Derecho Penal Argentino, Buenos Aires, TEA, 1963, p. 327. También véase A. Castro Moreno, El por qué y el para qué de las penas (análisis crítico sobre los fines de la pena), Madrid, Dykinson, 2008, p. 23.

${ }^{6} \mathrm{Al}$ respecto véanse S. Mir PUIG, Introducción a las bases del Derecho penal, 2. ${ }^{a}$ ed., Buenos Aires, BdF, 2002, pp. 50 y 51; E. Octavio De Toledo y Ubieto, Sobre el concepto de Derecho penal, Madrid, Universidad Complutense, 1981, p. 204, y M. DuRán MigLIARDI, «Justificación y legitimación político-criminal de la pena. Concepto, criterios y orientaciones en la actual jurisprudencia nacional», Política Criminal, vol. 4, núm. 8 , 
A pesar de estos indudables beneficios, las teorías netamente retributivas también encontrarían dificultades en su aplicación. Así, en la medida en que el sistema sólo atendía a la gravedad del injusto, sin tener en cuenta las características del delincuente, las penas aplicadas no lograban evitar altos índices de reincidencia, por no estar especialmente adecuadas a las particularidades del sujeto infractor al que se aplicaban ${ }^{7}$.

Ésta y muchas otras fueron las críticas que dirigieron los representantes de la escuela positivista italiana a la escuela clásica. Aquellos años en los que el Derecho resultaba un instrumento imprescindible de defensa contra el poder absoluto habían quedado atrás. La burguesía había tomado el control de la sociedad y los principios jurídicos ya habían logrado imponerse como garantía del individuo frente al Estado. En este nuevo escenario ya no era necesario poner límites a la crueldad de los castigos, sino que, incluso, los férreos principios instaurados en defensa de los sujetos infractores podían ser vistos como una amenaza para la protección de la socie$\mathrm{dad}^{8}$. Era necesario buscar nuevas armas que permitieran defender a las clases acomodadas de las menos favorecidas. Se necesitaban, en definitiva, nuevos medios de defensa de la sociedad ${ }^{\text {. }}$.

En este contexto irrumpe la revolución ideológica propuesta por la escuela positivista ${ }^{10}$, la cual pretendió resolver los problemas de las ciencias sociales partiendo de la medicina y la antropología ${ }^{11}$. Así, mientras la escuela clásica se basaba en la idea del libre albedrío y dejaba fuera del Derecho penal al sujeto considerado inimputable, la escuela positivista

diciembre de 2009, p. 277 (disponible en http://www.scielo.cl/scielo.php?pid=S071833992009000200001Escript=sci_abstract, fecha de consulta: 4 de abril de 2013). Véase también M. DuRÁn MigLiardi, «Teorías absolutas de la pena: origen y fundamentos. Conceptos y críticas fundamentales a la teoría de la retribución moral de Immanuel Kant a propósito del neo-retribucionismo y del neo-proporcionalismo en el Derecho penal actual», Revista de Filosofía, vol. 67, 2011, p. 123.

7 J. Frías Caballero, Temas de Derecho penal..., op. cit., p. 15.

8 E. R. Zaffaroni, El enemigo en Derecho Penal, Madrid, Dykinson, 2006, p. 89. p. 35 .

9 J. L. Peset y M. PeSET, Lombroso y la escuela positivista italiana, Madrid, CSIC, 1975,

${ }^{10}$ Cesare Lombroso se autoproclamó jefe de la escuela positivista. Al respecto se ha sostenido que, en realidad, lo que este autor hace es crear una disciplina causal-explicativa de la criminalidad que es la antropología criminal, mientras que los verdaderos creadores del positivismo fueron Enrico Ferri y Raffaele Garófalo. Cfr. L. JimÉnez DE AsúA, Principios de Derecho Penal..., op. cit., p. 56.

${ }_{11}$ J. L. Peset y M. Peset, Lombroso y la escuela positivista..., op. cit., p. 28. En opinión de Jiménez de Asúa, el positivismo mezcló una ciencia causal-explicativa, como es la criminología, con una ciencia cultural y normativa, que es el Derecho, produciendo un resultado híbrido. Cfr. L. Jiménez de AsúA, Principios de Derecho Penal..., op. cit., p. 56. 
fundó su planteamiento en la idea del determinismo, colocando a la enfermedad como centro del sistema penal ${ }^{12}$.

Los defensores del positivismo utilizaron a las ciencias experimentales para sostener que el delincuente es un sujeto enfermo ${ }^{13}$, eso es, un ser biológicamente inferior ${ }^{14}$. De acuerdo con esta concepción, los delincuentes deben ser eliminados, ya que no están preparados para vivir en sociedad. Esta enfermedad social inventada por el positivismo será la peligrosidad ${ }^{15}$, o bien, en palabras de Garófalo, la «temibilidad».

En la lógica del pensamiento positivista es necesario investigar al delincuente y no al delito ${ }^{16}$. El delito sólo es un síntoma de esa enfermedad que es la peligrosidad; podría decirse, por tanto, que el crimen es una manifestación de un estado peligroso ${ }^{17}$. De acuerdo con estos planteamientos, Lombroso, médico de profesión, se dedica a analizar la presencia en los delincuentes de determinadas características morfológicas ${ }^{18}$. Este autor considerará que la acumulación de una serie de características diferenciales en un mismo sujeto determinará su pertenencia a un «tipo delictivo de autor» ${ }^{19}$. Consecuentemente, las investigaciones desarrolladas por Lom-

12 J. L. Peset y M. Peset, Lombroso y la escuela positivista..., op. cit., p. 66. También al respecto J. Aróstegui Moreno, «La incidencia de la política criminal en las medidas de seguridad, en el principio de culpabilidad, en la Ley del Menor y en la Ley sobre violencia de género», en F. Pérez Álvarez (ed.), Temas cctuales de investigación en ciencias penales, Salamanca, Universidad de Salamanca, 2001, p. 281.

${ }_{13}$ El positivismo implicaba una verdadera revolución en cuanto al método de trabajo. Mientras que la escuela clásica utilizaba un método lógico abstracto, donde los juristas se limitaban al comentario de textos y leyes, la escuela positivista pretendía hacer uso del método experimental, planteando premisas que se comprobaban a través del trabajo científico. Cfr. J. L. Peset y M. Peset, Lombroso y la escuela positivista..., op. cit., p. 29.

${ }_{14}$ E. R. ZaFfaroni, El enemigo en Derecho Penal..., op. cit., p. 89.

15 G. DE Leo, La justicia de menores, Barcelona, Teide, 1985, p. 32.

${ }^{16}$ L. Jiménez de Asúa, Principios de Derecho Penal..., op. cit., p. 51. También véase F. CANO LÓPEZ, «La influencia del positivismo en la criminología y penología españolas. Orígenes y primeros pasos de la prevención especial como fin de la punición», en I. RIVERA BEIRAS (coord.), Mitologías y discursos sobre el castigo, Barcelona, Antrhopos, 2004, p. 63.

${ }_{17}$ Por tanto, y de acuerdo con la concepción sostenida por Garófalo, un delito consumado se castigaba con la misma intensidad que un delito en grado de tentativa. Cfr. J. L. Peset y M. Peset, Lombroso y la escuela positivista..., op. cit., p. 66.

${ }^{18}$ C. Lombroso, «Über der Ursprung, das Wesen und die Bestrebungen der neuen antropologistisch-kriminalistischen Schule in Italien», ZStW, núm. 1, 1881, p. 108. Sobre la vida y obra de Cesare Lombroso, ampliamente, F. KRÄPELIN, «Lombrosos Uomo delinquente», ZStW, núm. 5, 1885, p. 669.

19 Sobre los tipos de autor Lombroso señala lo siguiente: «Lo que verdaderamente constituye el tipo criminal, cosa que el público no tiene en cuenta, es la acumulación de un gran número de caracteres degenerativos en el mismo individuo, lo cual no se observa sino por excepción en el hombre normal (1 por 400), y aun en los mismos delincuentes se observa mucho más frecuentemente en la criminalidad grave que en la ligera [...] cada especie de 
broso lo llevan a sostener la existencia de verdaderos delincuentes natos que, al tener una inclinación al delito determinada por factores orgánicos, no pueden ser redimidos ${ }^{20}$.

En una concepción semejante, la pena no podrá ser concebida como un castigo ni tendrá, lógicamente, carácter retributivo, sino que será, principalmente, un medio de defensa social ${ }^{21}$. De esta manera, los autores positivistas sustituyen el principio jurídico de la responsabilidad moral - fundada en la voluntad libre y en la inteligencia normal humanas, esto es, en la culpabilidad por los actos cometidos- por el principio de la responsabilidad social o legal de los individuos, es decir, por aquella responsabilidad que deriva del hecho de vivir en sociedad y que se funda solamente en necesidades de defensa ${ }^{22}$.

Así, se considerará que la sociedad, a través de la pena, debe defenderse de estos sujetos que no son aptos para llevar una vida ajustada a las leyes, y para que la pena pueda lograr el objetivo de defensa social que se propone no podrá ser proporcional a la gravedad del hecho cometido, sino que deberá ser proporcional a la peligrosidad del autor ${ }^{23}$. Además, al ser la pena un verdadero tratamiento cuya justificación se halla en la peligrosidad del individuo, pierde todo sentido, en opinión de Ferri, la existencia de penas de duración determinada. Así lo expresa con claridad este autor cuando señala: «Cuando hoy el juez — después de realizar los cálculos de las fracciones aritméticas - condena a un delincuente, por ejemplo, a nueve años, siete meses y veinte días de reclusión, aparece claro lo absurdo del sistema, como sería absurdo que el médico en la puerta del hospital fijara de antemano los meses y los días de permanencia del enfermo en el establecimiento en términos tales que tuviera que permanecer en él todo ese tiempo, aunque antes de

delito tiene a su tipo particular. Así, en general, los ladrones tienen una movilidad notable de la cara y de las manos; el ojo pequeño, errante, movilísimo, a menudo oblicuo; las cejas pobladas y juntas; la nariz torcida y chata; escasez de barba; no siempre espesa la cabellera; la frente casi siempre pequeña y huida. Tanto los ladrones como los estupradores tienen a menudo el pabellón de la oreja inserto en forma de asa». Cfr. J. L. Peset y M. Peset, Lombroso y la escuela positivista italiana..., p. 435.

${ }^{20} \mathrm{~J}$. ANTÓN OneCA, Obras..., op. cit., p. 40. Sobre los factores que provocan la delincuencia en la concepción de Ferri véase E. FERRI, «Das Verbrechen in seiner Abhängigkeit von dem jährlichen Temperaturwechsel», ZStW, núm. 2, 1882, p. 11.

${ }^{21}$ En la concepción de Garófalo la pena es un medio de selección de individuos. El autor entiende que, una vez que el delincuente ha manifestado que no está adaptado para la vida social, la colectividad, a través de la pena, reacciona expulsándole de la sociedad, por lo cual la represión será principalmente segregatoria. Cfr. J. AnTón OnECA, Obras..., op. cit., p. 39.

${ }_{22}$ R. C. NuÑEz, Derecho Penal Argentino. Parte General (I), Buenos Aires, Tipográfica Editorial Argentina, 1959, p. 59.

${ }_{23}$ F. CANO LÓPEZ, «La influencia del positivismo en la criminología...», op. cit., p. 70. 
cumplirse se encontrara ya curado, debiendo, en cambio, salir al término del plazo aunque la curación no se hubiera conseguido» ${ }^{24}$.

Como se deduce de lo expuesto, esta concepción supone, necesariamente, la criminalización de los sectores más desfavorecidos de la sociedad $^{25}$ e implica la instauración de un verdadero régimen totalitario. De hecho, estas ideas fueron utilizadas algún tiempo después por los Estados totalitarios para cumplir su objetivo de suprimir al individuo ${ }^{26}$. No obstante, es necesario señalar que esta concepción, en su planteamiento puro, era irrealizable, ya que era imposible que estas ideas se vieran plasmadas en la legislación tal como se formulaban de forma teórica en el ámbito doctrinal. Ni siquiera el Proyecto de Reforma del Código Penal italiano de 1921, elaborado por Ferri, pudo absorber la totalidad de estas ideas ${ }^{27}$. Además, el grado de enfrentamiento con la escuela clásica dificultó desde su inicio que una revolución de este calado pudiera ver la luz. En esta situación, por tanto, resultaba imprescindible la evolución de postu-

${ }^{24}$ E. FERRI, Principios de Derecho criminal. Delincuente y delito en la ciencia, en la legislación y en la Jurisprudencia, trad. de José Arturo Rodríguez Muñoz, 1. ${ }^{a}$ ed., Madrid, Reus, 1933, p. 310. Especialmente ejemplificativa de la concepción de Ferri será la experiencia que el autor relata en la cita núm. 1 del segundo capítulo de su obra (p. 240): «Durante mis observaciones sobe los delincuentes tuve ocasión muchas veces de poner de manifiesto la especial tendencia delictiva del tipo criminal (sobre todo deduciéndola de la fisonomía de los sujetos). Examinando en 1880 en Bolonia a 700 soldados como tipos normales contrapuestos a 700 reclusos de Pesaro y Castelfranco y a 400 locos de manicomios de Pesaro y Bolonia, un día, viendo avanzar para el reconocimiento a un soldado, dije al teniente médico que me acompañaba que aquel individuo era un homicida. El teniente me hizo observar que estos delincuentes no eran admitidos en el ejército. Pero aquel soldado, interrogado por mí, confesó que había sido procesado por un homicidio cometido cuando era un muchacho, pero que no había recaído condena (tal vez por no haberse podido probar el discernimiento) y que por eso se encontraba en el servicio de las armas. Otra vez, en 1889, habiendo llevado a mis alumnos (entre los que se encontraban Scipion Sighele y Hugo Ojetti) al Reformatorio de Tivoli, señalé entre los muchachos que se encontraban en el patio a uno que presentaba el tipo de homicida. El director me indicó que en aquel Reformatorio no podía haber ningún delincuente, porque estaba destinado sólo a muchachos díscolos y rebeldes a la autoridad de sus padres (art. 222 del Código Civil). Pero interrogando a aquel joven supimos que estaba allí transitoriamente y que iba a pasar al Reformatorio de Turín por haber sido condenado a causa de haber dado muerte por celos a un hermanito suyo a quien destrozó la cabeza a golpes mientras dormía». Una completa revisión de la vida de Enrico Ferri puede encontrarse en G. DANIEL, «Enrico Ferri», ZStW, núm. 50, 1930, p. 475.

${ }_{25}$ F. CANo LóPeZ, «La influencia del positivismo en la criminología...», op. cit., p. 72.

${ }^{26}$ En opinión de Zaffaroni, la llegada del pensamiento positivista fue equivalente al regreso del sistema inquisitorio. Cfr. E. R. ZAFFaroni, El enemigo en Derecho Penal..., op. cit., p. 89. También en este sentido J. L. PESET y M. PESET, Lombroso y la escuela positivista..., op. cit., p. 70, y J. Frías CaBAlLERO, Temas de Derecho penal..., op. cit., p. 11.

${ }^{27}$ L. JiméneZ de Asúa, Principios de Derecho Penal..., op. cit., p. 56. 
ras intermedias que pudieran matizar la radicalización de las ideas imperantes. Dentro de esta orientación moderna destacó la escuela sociológica alemana encabezada por Frank Von Liszt.

Entendemos que la concepción sostenida por Von Liszt no puede ser definida como una postura ecléctica, ya que su teoría tiene significativos puntos de contacto con las ideas italianas. En este sentido, se ha caracterizado a Von Liszt como el más normativista y matizado de los positivistas ${ }^{28}$. Uno de los principales aciertos de este autor es, precisamente, no caer en el error de la escuela italiana de utilizar el método experimental para el análisis del Derecho. Por otro lado, el autor alemán separa las necesidades del trabajo criminológico del Derecho positivo. De esta forma, el jurista alemán utiliza el método jurídico para analizar el Derecho y el método experimental para los trabajos criminológicos ${ }^{29}$. En su visión, las conclusiones que se extraen de la criminología sirven a la política criminal; es decir, la información sobre el delincuente que aporta la criminología permitirá proponer reformas de lege ferenda, pero nunca podrá ser utilizada para la interpretación de las normas penales ${ }^{30}$.

A pesar de ello, tal como se ha indicado, también existen importantes similitudes con la escuela positivista. Von Liszt parte del determinismo del hombre, tal como lo hacían Lombroso y sus discípulos ${ }^{31}$. No obstante, este autor rechaza la idea de que existan hombres que estén determinados al delito desde su nacimiento (y, por tanto, la existencia de tipos de autor) y prefiere concebir al delincuente como el resultado del ambiente social en el que se desenvuelve ${ }^{32}$. Así, la clasificación tripartita de delincuentes —ocasionales, motivables e incorregibles- ${ }^{33}$, que caracterizará su postura, tendrá efectos y relevancia sólo en el ámbito de la determinación

${ }^{28}$ E. R. Zaffaroni, El enemigo en Derecho Penal..., op. cit., p. 91.

29 L. JiméneZ DE AsúA, Principios de Derecho Penal..., op. cit., p. 3.

30 V. Gómez Martín, El Derecho Penal de Autor, Valencia, Tirant lo Blanch, 2007, p. 46.

$31 \mathrm{Al}$ respecto véase J. Cuello Contreras, Culpabilidad e imprudencia, Madrid, Ministerio de Justicia, 1990, p. 47.

32 F. Von Liszt, Tratado de Derecho Penal, Buenos Aires, Valletta, 2007, p. 244.

33 Von Liszt propuso una clasificación de delincuentes en la que distinguía entre:

1) Delincuentes ocasionales: para quienes el hecho punible es sólo un episodio, por lo que el peligro de repetición de hechos delictivos es mínimo y la corrección sistemática no tiene razón de ser. En estos casos la pena sólo debe ser intimidación, es decir, una advertencia relativamente contundente.

2) Delincuentes corregibles: se trata de delincuentes habituales que, aunque propensos por una predisposición hereditaria o adquirida, todavía no están perdidos sin salvación posible. Frente a estos sujetos la pena deberá cumplir una función correctora. Para ello Von Liszt propone penas privativas de libertad de una duración mínima de un año y un máximo de cinco, que deberían iniciarse con un aislamiento celular para pasar, posteriormente y de 
de la pena. De esta manera, el concepto de peligrosidad también tendrá un lugar destacado en la teoría de Von Liszt. Así, a pesar de que el penalista alemán puso el acento en el autor del delito, no dejó nunca de tener presente que el objeto de la prohibición penal seguía estando en el hecho concreto. Para la escuela moderna, los presupuestos de la punibilidad debían determinarse con criterios de Derecho penal del hecho, mientras que las consecuencias jurídicas debían determinarse por criterios de Derecho penal de autor. De acuerdo con esta concepción, el Derecho penal determinaba si se debía penar y la política criminal, basándose en el criterio de la peligrosidad y las necesidades de defensa de la sociedad, determinaba cómo debía aplicarse esa pena ${ }^{34}$.

La escuela sociológica alemana no renuncia tampoco al concepto de culpabilidad. No obstante, la culpabilidad no tendrá que ver con la libertad de poder obrar de otro modo - criterio utilizado por la escuela clásica-, sino que será equivalente a la responsabilidad que se tiene por el resultado. En esta teoría, la responsabilidad no significaba nada más que hacer responsable de su hecho al delincuente sano mentalmente ${ }^{35}$. A su vez, la negación del libre albedrío impuso a Von Liszt la necesidad de encontrar un concepto de imputabilidad acorde con el determinismo ${ }^{36}$. Así, la

forma progresiva, a la vida en régimen de comunidad. En estos casos los castigos corporales y las penas disciplinarias estarían totalmente prohibidos.

3) Delincuentes incorregibles: aquellos delincuentes habituales que no pueden ser recuperados y frente a los cuales sólo cabe la segregación o inocuización. Para ellos Von Liszt propone la pena de prisión por tiempo indeterminado, que debería cumplirse en establecimientos especiales, incluyendo la posibilidad de someter a estos sujetos a trabajos forzados. Se trataría de un régimen de «esclavitud penal» donde no podría prescindirse del castigo corporal como medida disciplinaria. Cfr. F. Von LiszT, La idea del fin en Derecho penal. Programa de la Universidad de Marburgo de 1882, introducción y nota biográfica de J. M. Zugaldía Espinar, trad. de C. Pérez del Valle, Granada, Comares, 1995, pp. 83 y ss. Al respecto, ampliamente, T. STÄCKER, Die Franz von Liszt-Schule und Ibre Auswirkungen auf die deutsche Strafrechtsentwicklung, Baden-Baden, Nomos, 2012, p. 35.

34 V. Gómez Martín, El Derecho Penal de Autor..., op. cit., p. 46.

$35 \mathrm{Al}$ respecto véase E. HeINITZ, «Franz von Liszt als Dogmatiker», ZStW, núm. 81, 1969 , p. 588. La teoría de la culpabilidad de Von Liszt se basaba en una relación cuantitativa y subjetiva entre el autor y su hecho. Esta relación subjetiva era dolosa, cuando el autor quería el resultado del hecho o al menos lo había tenido en cuenta, o imprudente, cuando el autor no había querido el resultado pero lo había ocasionado por indiferencia o desconocimiento. La afirmación de que alguien había actuado dolosamente se basaba en que la conducta había sido realizada voluntariamente, pero también incluía la necesidad de la conciencia de su ilicitud. Se trataba, por tanto, de un concepto psicológico de culpabilidad. Cfr. G. Quintero Olivares, «Franz von Liszt y la ciencia penal española», en J. Cerezo Mir et al. (ed.), El nuevo Código Penal: presupuestos y fundamentos. Libro homenaje al profesor doctor don Ángel Torío López, Granada, Comares, 1999, p. 207.

36 Así, según la construcción de von Liszt, el reconocimiento de que en el delito han 
salud mental necesaria para la culpabilidad (imputabilidad) fue concebida como «posibilidad de determinación normal por motivos»: «Quien reacciona a los motivos de forma anormal, es decir, de modo diferente al hombre medio normal, no es imputable y, por tanto, no puede ser penado» ${ }^{37}$.

En el ámbito de las consecuencias jurídicas del delito, el autor alemán parte de la necesidad de la pena para el mantenimiento del orden jurídico y de la idoneidad de la misma para conseguir esa meta, aunque sólo sea de forma limitada ${ }^{38}$. Así, sustituye la pena retributiva por la pena protectora, «la pena con arreglo a fin», y pasa a un primer plano la idea de la prevención especial, aunque sin dejar de lado la prevención general. Central en la concepción de Von Liszt será la misión de la pena, que deberá actuar sobre el delincuente de forma adecuada a las peculiaridades del mismo. Así concebida la pena no se dirigirá contra el delito, sino contra los delincuentes ${ }^{39}$, y no encontrará su razón de ser en la culpabilidad por el hecho, sino en la incapacidad del sujeto ${ }^{40}$. Von Liszt criticaba que la doctrina dominante hasta el momento se afanaba por establecer una pena para «el hecho que no ha cometido ningún autor». Por entonces se trataba de penas que se adecuaban al concepto de delito, a la abstracción del legislador, y que respondían a la pregunta acerca de «qué merece el hurto, la violación, el asesinato o el perjurio, en lugar de preguntarse qué ha merecido este ladrón, este asesino, este perjuro o este violador» ${ }^{41}$. Para Von Liszt, hecho y autor no eran términos contrapuestos, ya que «no existe delito que no haya sido cometido por un delincuente» ${ }^{42}$.

Resulta relevante destacar que el jurista alemán mostró especial preocupación por las circunstancias de su época, razón por la que se ocupó, muy par-

intervenido factores determinantes externos no debe ser motivo para negarle al delincuente la condición de hombre que ha decidido en el sentido de la imputabilidad. Cfr. G. QuinTERO Olivares, «Franz von Liszt y la ciencia penal española», op. cit., p. 208.

37 Sobre el concepto de imputabilidad en la teoría de Von Liszt véase F. Von LiszT, «Die strafrechtliche Zurechnungsfähigkeit», $Z S t W$, núm. 17, 1897, p. 70, y E. HEINITZ, «Franz von Liszt als Dogmatiker», ZStW, núm. 81, 1969, p. 585.

$38 \mathrm{Al}$ respecto véase W. NAUCKE, «Die Kriminalpolitik des Marburger Programms 1882», ZStW, 94 (Heft 3), 1982, p. 525.

39 F. Von Liszt, La idea del fin en Derecho penal..., op. cit., p. 83.

40 P. Bockelmann, «Franz von Liszt und die kriminalpolitische Konzeption des allgemeinen Teils», ZStW, núm. 81, 1969, p. 597.

${ }^{41}$ F. Von LiszT, La idea del fin en Derecho penal..., op. cit., p. 92.

$42 \mathrm{Ibid}$. En la concepción de Von Liszt, el objetivo de la lucha contra el crimen era la protección de bienes jurídicos y el medio para protegerlos era atacar las causas que provocan las amenazas. Al respecto véanse P. Bockelmann, «Franz von Liszt und die kriminalpolitische...», op. cit., p. 597, y T. STÄCKER, Die Franz von Liszt-Schule und Ibre Auswirkungen auf die deutsche Strafrechtsentwicklung..., op. cit., p. 36. 
ticularmente, del tratamiento del delincuente habitual, dedicando especiales esfuerzos por combatir al que él mismo llamara «delincuente incorregible» ${ }^{43}$. Para este tipo de sujetos sumamente peligrosos Von Liszt proponía la aplicación de penas indeterminadas. Según sus propias palabras, debería establecerse una verdadera «esclavitud penal con la obligación de trabajar y muy posiblemente con la utilización de la fuerza del trabajo. Apenas podría prescindirse del castigo corporal como pena disciplinaria» ${ }^{44}$.

Las «moderadas» ideas de Von Liszt tendrán un carácter demasiado positivista para su implantación en el Código Penal alemán y se toparán con la resistencia de los defensores de las ideas clásicas, lo cual retrasará y dificultará la reforma del Código Penal alemán. En este contexto, el Proyecto de Reforma del Código Penal suizo de 1893 elaborado por Carl Stoss incorpora una novedosa opción que permite una nueva vía de entendimiento. Stoss reemplaza la pena indeterminada por medidas administrativas policiales, creando, de esta forma, las medidas de seguridad ${ }^{45}$. De acuerdo con el nuevo modelo, resultarán aplicables penas adecuadas a la gravedad del hecho y a la culpabilidad para los sujetos imputables y medidas indeterminadas para los sujetos peligrosos. Se combina, por tanto, en un mismo cuerpo normativo, un Derecho penal idealista-retribucionista y otro determinista-progresista. Se trata, en consecuencia, de conjugar ideas en principio irreconciliables.

Son momentos en que las circunstancias animan a hacer un esfuerzo por acercar posturas. En este contexto, la doctrina se vio «obligada» a construir una extraña convivencia entre culpabilidad y peligrosidad. La ciencia penal construye entonces su sistema con dos conceptos totalmente antagónicos y contradictorios entre sí. Por una parte, el libre albedrío, que fundamenta la culpabilidad, y, por otra, el determinismo, que funda-

\footnotetext{
${ }^{43}$ Muñoz Conde resalta la especial preocupación que, al igual que muchos penalistas de su tiempo, tenía Von Liszt con respecto al delincuente incorregible. En su obra se pone de manifiesto el recelo que este autor guarda en relación con los vagabundos y delincuentes de poca monta y, más aún, con respecto a aquellos que cometían delitos habitualmente. Así, se trataba de una preocupación típica de un penalista que vivía en la Alemania de fines del siglo XIX, caracterizada por el orden y la prosperidad. Por entonces la preocupación por los entornos sociales marginales y, en especial, por la criminalidad habitual que había aumentado enormemente con la industrialización y el crecimiento de la población urbana, se reflejaba en el ámbito jurídico en la aprobación de medidas represivas de corte puramente punitivo. F. MuÑoz Conde, «La herencia de Franz von Liszt», Revista Penal, núm. 27, 2001, p. 164.

${ }^{44}$ F. Von Liszt, La idea del fin en Derecho penal..., op. cit., p. 87.

${ }^{45}$ Sobre la concepción de este autor véase C. STOSs, «Strafe und sichernde Massnahme», en Schweizerische Zeitschrift für Strafrecht, año 8, Bern, 1905, p. 1.
} 
menta la peligrosidad ${ }^{46}$. Para poder mantener un sistema donde la pena fuera adecuada a la gravedad del hecho y a la culpabilidad del autor, y, por tanto, fuera de duración determinada, los representantes de la escuela clásica estuvieron dispuestos a admitir que existen determinados sujetos, los «peligrosos», que están determinados al delito, por lo que no merecen gozar de derechos y garantías y deben quedar bajo la tutela y acción benefactora del Estado ${ }^{47}$.

Los representantes de la escuela moderna también vieron en el proyecto de Stoss algunas de sus ideas político-criminales más importantes realizadas, lo que podía significar una base aceptable para un compromiso. Especialmente significativo fue el hecho de que Von Liszt admitiera la validez de este sistema de doble vía. Así, aunque este autor entendía que la separación entre pena y medida no era imaginable y que carecía totalmente de sentido, como hombre práctico aceptó esta nueva concepción y la consideró como un paso adelante de la escuela moderna ${ }^{48}$.

De esta forma, la introducción de un sistema dualista hizo posible que se produjera, finalmente, un acercamiento entre las dos posturas. La doble vía resultó ser para ambos un compromiso aceptable, ya que la escuela moderna pudo tener un sistema de medidas orientado al fin y la escuela clásica pudo mantener la pena adecuada a la culpabilidad. Ambos también aceptaron el modelo de la prevención. La escuela clásica lo hizo poniendo el acento en la prevención general, con lo que a través de la pena se manifestaba la autoridad del Estado, mientras que la escuela moderna aceptó un modelo individual-preventivo donde el efecto se individualizaba sobre cada tipo de criminal ${ }^{49}$.

A principios del siglo xx los altos índices de reincidencia de la delincuencia en Alemania determinaron que la reforma del Código Penal fuera vista como una necesidad acuciante para poder solucionar el problema del

${ }^{46}$ J. Bustos Ramírez, «Los mitos de la ciencia penal del siglo xx: la culpabilidad y la peligrosidad», en Díez Ripollés et al. (eds.), La ciencia del Derecho penal ante el nuevo siglo. Libro homenaje al profesor doctor don José Cerezo Mir, Madrid, Tecnos, 2002, p. 6.

${ }_{47}$ Ibid., op. cit., p. 6. Al respecto sostiene Von Liszt que entre determinismo e indeterminismo era imposible lograr un acuerdo sistemático; no obstante, el resultado de las discusiones fue que una gran parte de los representantes del libre albedrío profesaran un indeterminismo relativo. Cfr. F. Von Liszt, Tratado de Derecho Penal..., op. cit., p. 245.

${ }_{48}$ W. FrISCH, «Das Marburger Programm und die Maßregeln der Besserung und Sicherung», ZStW, núm. 94, 1982, p. 571. También véanse A. GARCíA-PAblos DE Molina, Introducción al Derecho Penal, 4. ${ }^{a}$ ed., Madrid, Ramón Areces, 2006, p. 353, y J. Cuello CONTRERAs, Culpabilidad e imprudencia..., op. cit., p. 48.

49 J. D. JANSING, Nachträgliche Sicherungsverwahrung Entwicklungslinien in der Dogmatik der Sicherungsverwabrung, Münster, LIT, 2004, p. 18. 
delincuente habitual. Ésta y otras circunstancias impulsan el desarrollo de múltiples proyectos de reforma que no llegan a entrar en vigor ${ }^{50}$. En estos textos prelegislativos se propone la incorporación de un sistema de doble vía penas-medidas de seguridad sobre la base de la solución de compromiso alcanzado entre la escuela moderna y la escuela clásica ${ }^{51}$. Se trata, como es sabido, de una época especialmente prolífica para el desarrollo del Derecho penal. Así, durante la República de Weimar (periodo comprendido entre 1918 y 1933) se logra establecer una clara delimitación entre la criminología y la dogmática al dividirse el estudio del delito en dos vertientes: la causal-explicativa (criminológica) y la comprensivo-axiológica (dogmática). Esta circunstancia favorecerá de manera determinante el desarrollo de la dogmática y el perfeccionamiento de la teoría del delito ${ }^{52}$.

\section{Las medidas de seguridad en la época nacionalsocialista}

Con la llegada al poder en 1933 del gobierno nacionalsocialista cambia radicalmente el escenario del Derecho alemán. Puede sostenerse que la característica más destacada de este periodo es el abandono del individualismo y la racionalidad, instaurándose un sistema donde primaba, de forma absoluta, la utilización de la ley para la defensa de la colectividad ${ }^{53}$. En el ámbito concreto del Derecho penal se deja atrás la idea de un derecho protector de bienes jurídicos; de acuerdo con la nueva concepción, el sujeto no será castigado por lesionar o poner en peligro bienes jurídicos, sino por exteriorizar «una actitud interna reprochable» al traicionar a la colectividad mediante la infracción del deber de fidelidad hacia aquélla. Así, se pasó de un Derecho que ponía el acento en la lesión del bien jurídico, a la noción de delito como hecho contrario a la comunidad, en un

\footnotetext{
${ }^{50}$ Nos referimos a los Proyectos de Reforma de 1909, 1911 (Contraproyecto presentado por los profesores Kahl, Von Lilienthal, Von Liszt y Goldschmidt), 1913, 1919, 1922, 1925, 1927 y 1930. Al respecto véanse K. von LiLienthal, «Strafen und Sichernde Maßnahmen in der Reichstagvorschlage», ZStW, núm. 48, 1928, p. 300; E. MEZgER, «Kriminologische Grundlagen von Strafe und Sicherung im Strafgesetzentwurf 1927», ZStW, núm. 49, 1929, p. 171, y H. KRIENER, Die Berücksichtigung Kriminalbiologischen Forderungen im geltenden und im kommenden Recht, Würzburg, 1936, p. 7.

51 E. Mezger, Tratado de Derecho Penal, t. I, trad. de la 2. ${ }^{a}$ ed. alemana de 1933 por J. A. Rodríguez Muñoz, Madrid, Edersa, 1955, p. 86.

52 F. Muñoz Conde, Edmund Mezger y el Derecho penal de su tiempo. Estudios sobre el Derecho penal en el nacionalsocialismo, 4. ${ }^{\text {e }}$ ed., Valencia, Tirant lo Blanch, 2003, p. 32.

53 A. Hoyer, «Ciencia del Derecho penal y nacionalsocialismo», Revista Penal, núm. 23, enero de 2009, p. 42.
} 
contexto donde la persona individual carecía de valor más allá de su pertenencia a la sociedad ${ }^{54}$.

De especial relevancia será la reforma operada al Código Penal en 1935, que modifica el $\S 2$ StGB para incluir expresamente la posibilidad de aplicar la analogía im malam partem. Según señala el precepto en cuestión, una conducta será castigada cuando sea considerada delictiva de acuerdo el texto de la ley o bien cuando el «pensamiento jurídico que la subyace y el sano sentimiento popular» así lo determinen ${ }^{55}$. Esta reforma servirá para cumplir con el objetivo del régimen de impedir que la rigidez de un Derecho formalista pudiera impedir que los delincuentes recibieran su «merecido castigo». A partir de entonces, los tipos penales perderán su función de delimitación del ámbito de lo injusto para pasar solamente a perfilar un concreto tipo de delito y de autor ${ }^{56}$.

Especialmente destacable es el hecho de que los penalistas del régimen nacionalsocialista compartieran con los positivistas su obsesión por la clasificación de delincuentes. No obstante, se apartarán de las ideas lombrosianas en varios aspectos. Así, en opinión de Edmund Mezger, las causas hereditarias no serán el único factor que determinará al sujeto a delinquir, sino que el delito será el producto de la disposición y del medio, esto es, de la índole genuina del delincuente en el momento del acto y de las relaciones o condiciones exteriores que circundan al delincuente en este momento ${ }^{57}$. Según la concepción de este autor, no debe hablarse de «un delin-

54 V. Gómez Martín, El Derecho Penal de Autor..., op. cit., p. 143.

551 de septiembre de 1935-4 de febrero de 1946: «\$2. [1] Bestraft wird, wer eine Tat begeht, die das Gesetz für strafbar erklärt oder die nach dem Grundgedanken eines Strafgesetzes und nach gesundem Volksempfinden Bestrafung verdient. [2] Findet auf die Tat kein bestimmtes Strafgesetz unmittelbar Anwendung, so wird die Tat nach dem Gesetz bestraft, dessen Grundgedanke auf sie am besten zutrifft».

56 A. HOYER, «Ciencia del Derecho penal y nacionalsocialismo», op. cit., p. 42. Sobre la utilización de la analogía en el Derecho penal nacionalsocialista véase, ampliamente, J. VoGEL, «Einflüsse des Nationalsozialismus auf das Strafrecht», ZStW, núm. 115, 2003, p. 651.

57 A su vez, en relación con el concepto de disposición, Mezger distinguirá tres factores: la «disposición heredada», que se refiere a aquella disposición que un hombre recibe en virtud de la unión de dos plasmas germinales de sus progenitores para todo el curso de la vida; la «disposición innata», que no se corresponde con la heredada, pues significa tanto como la disposición heredada con sus modificaciones y alteraciones, donde pertenecen todos los influjos como el alcohol o la tuberculosis que han alterado y empeorado la disposición heredada del individuo, y finalmente, la «disposición adquirida» $\mathrm{o}$ «personalidad», que representa la totalidad de los factores endógenos, aquella disposición que sobre la base de la disposición heredada encierra en sí todos los influjos y efectos que hasta aquel momento han alterado y modificado en buen o mal sentido la disposición heredada y la innata. Cfr. E. Mezger, Criminología, trad. de José Arturo Rodríguez Muño, Madrid, Revista de Derecho Privado, 1942, p. 250. 
cuente nato», sino de «delincuentes natos», ya que no puede admitirse que exista un tipo unitario de delincuente corporal y anímicamente estigmatizado, sino que las circunstancias y condiciones que llevan a la delincuencia pueden presentarse de muchas maneras diferentes. Ello lleva a que no deba centrarse el interés criminológico en un tipo especial de hombre, sino en la totalidad de los tipos humanos ${ }^{58}$.

A pesar de estas diferencias, Mezger acepta el indudable valor de los estudios de Lombroso al reconocer que fue el primero en promover la consideración científico-causal del delito y un tratamiento político-criminal del problema del delincuente apoyado en la primera consideración. Este autor entenderá imprescindible una investigación exacta de los fundamentos positivos de la criminalidad sobre una base científico-causal, especialmente biológica, psicológica y psicopatológica, de forma que, en el futuro, fuera posible obtener una amplia fenomenología de autores ${ }^{59}$.

Siguiendo estas ideas, múltiples fueron las propuestas presentadas por los autores para clasificar a los delincuentes desde los más variados puntos de vista. Al respecto, sostenía Franz Exner que no existe ninguna clasificación técnica y absolutamente cierta, sino muchos esquemas de clasificación distintos según los fines a que la misma ha de servir. No obstante, estas clasificaciones sólo tendrán valor en cuanto los grupos representados sean dignos de tratamiento y apreciación diferenciados. Teniendo en cuenta este criterio, Exner señalaba las clasificaciones que, a su juicio, resultaban de mayor relevancia. Así, en su Biología criminal distinguía ${ }^{60}$ :

1. Los «tipos biológico-hereditarios», que respondían a la pregunta de por qué el sujeto ha llegado a este tipo de vida. Dentro de los cuales se encontraban:

- los «endógenos», en los que el desarrollo de la personalidad del delincuente se apoya en la disposición;

- los «exógenos», en los que el desarrollo de la personalidad del delincuente se apoya en los influjos del mundo circundante.

2. Los «tipos sociológico-criminales», donde se valora el grado de energía desplegada. Aquí destacan:

${ }^{58}$ Mezger rechaza de esta manera lo que considera una pretendida solución «generalizadora». Cfr. E. Mezger, Criminología..., op. cit., p. 34.

59 Ibid., p. 29.

${ }^{60}$ F. EXNER, Biología criminal en sus rasgos fundamentales, trad. de Juan del Rosal, Barcelona, Bosch, 1946, p. 346. 
— los «delincuentes de estado peligrosos», en los que la importancia de los ataques que de ellos se espera los convierte en sujetos peligrosos;

- los «delincuentes de estado gravosos», aquellos que cometen hechos delictivos con asiduidad, pero donde los hechos son de menor entidad.

3. Los «tipos político-criminales». Aquí se clasifican los sujetos según el método de lucha político-criminal apropiada para ellos, debiendo distinguirse entre:

- los incorregibles;

- los corregibles.

A pesar de ello, Exner consideraba que la clasificación fundamental era la que distinguía entre delincuentes de estado y delincuentes ocasionales, ya que era la utilizada por el legislador para decidir la aplicación de penas y de medidas de seguridad ${ }^{61}$. En efecto, la Ley contra delincuentes habituales peligrosos y sobre medidas de aseguramiento y corrección, aprobada el 24 de noviembre de 1933, incorporó, en el Código Penal alemán, luego de muchos años de intentos fracasados, un sistema dualista que incluía penas y medidas de seguridad. Así, según la consideración de Exner, las penas resultarían aplicables a los delincuentes ocasionales y las medidas de seguridad a los delincuentes de estado, dentro de los cuales, a su vez, sería necesario distinguir a los corregibles, que son aquellos para los que estaban destinadas las medidas de corrección, y los incorregibles, a quienes debían aplicarse las medidas de aseguramiento ${ }^{62}$.

La Ley contra los delincuentes habituales fue la plasmación en la legislación alemana de las ideas que venían abriéndose paso en el pensamiento jurídico desde varias décadas atrás. Esta norma asumió la solución de compromiso que habían aceptado como válida los representantes de la escuela clásica y de la escuela sociológica alemana ${ }^{63}$. Esta circunstancia queda

${ }^{61}$ Ibid., p. 356.

${ }^{62}$ Ibid.

${ }^{63}$ J. D. Jansing, Nachträgliche Sicherungsverwahrung..., op. cit., p. 30. En este sentido señala Cano Paños que la custodia de seguridad se retrotrae a una concepción político-criminal prefascista que estaba extendida en la Europa continental de la época. Cfr. M. CANO PAÑOS, «El marco jurídico y criminológico de la custodia de seguridad (Sicherungsverwabrung) en el Derecho penal alemán», Cuadernos de Política Criminal, núm. 91, 2007, p. 208. También véanse T. BARTSCH, Sicherungsverwahrung - Recht, Vollzug, aktuelle Probleme, Baden-Baden, Nomos, 2010, p. 30; B. Müller-Christmann, «Zur Einarbeitung und Wiederholung», Juristische Schulung, núm. 10, 1990, p. 802, y K. HöFfen y J. KasPaR, 
claramente plasmada en la introducción del trabajo que Exner dedicara al comentario de la nueva norma: «Es un largo y espinoso camino al final del cual se encuentra esta Ley. Hace cincuenta y un años ha solicitado Frank von Liszt el armamento legal eficaz para la lucha contra la delincuencia disposicional jen vano! Hace cuarenta años el primer proyecto suizo ha mostrado el camino con el que se cumpliría con esta misión jen vano! Hace veinticinco años el viejo Reich ha recorrido el camino en un Primer Anteproyecto para Alemania jen vano! Finalmente, después de la guerra parecía haber llegado el momento; gobierno y Parlamento se ocuparon durante un decenio completo en deliberaciones y resoluciones ¡otra vez en vano! El Estado de Weimar fue demasiado débil para completar la tarea y, como el último Proyecto muestra, también demasiado endeble» ${ }^{64}$.

No obstante, el aparato jurídico nacionalsocialista no se limitó a incorporar a la legislación penal la solución de compromiso aceptada por las escuelas, sino que también le imprimió a este sistema dualista un carácter marcadamente autoritario que escapaba de los planteamientos iniciales ${ }^{65}$. En este sentido, un claro indicio de la diferencia esencial de la ley con los proyectos anteriores es la circunstancia de que la representación de Von Liszt como un autor «positivista»o «liberal-socialista» fuera reiteradamente difamada sobre la base de que, en su construcción, la idea de la necesaria defensa de la sociedad no tuvo el lugar que le correspondía ${ }^{66}$.

Centrándonos en las características de la nueva ley, una de las medidas más controvertidas fue la incorporación del $\S 20 . a)^{67}$. Esta norma establecía la posibilidad de aplicar una pena de presidio a aquel sujeto que llevara a cabo tres hechos delictivos dolosos, siempre y cuando de la evaluación general de los hechos pudiera desprenderse que el sujeto era un delincuente habi-

«Warum das Abstandsgebot die Probleme der Sicherungsverwahrung nicht lösen kann? Zugleich ein Beitrag zu den Aporien der Zweispurigkeit des strafrechtlichen Sanktionssystems», ZStW, núm. 124, 2012, p. 87.

${ }^{64}$ F. EXNER, «Das System der sichernden und bessernden Maßregeln nach dem Gesetz v. 24. November 1933», ZStW, núm. 53, 1934, p. 629.

${ }^{65}$ H. J. KoestLeR, Der Begriff des «gefährlichen Gewohnheitsverbrechers» als Ergebnis einer Entwickung: Ein Beitrag zu einer Auslegung, Dresden, Dittert, 1938, p. 74. En este sentido se ha sostenido que las medidas de seguridad instauradas por el régimen nacionalsocialista eran verdaderas «penas de seguridad». Cfr. G. Meyer, Die Behandlung des Kampfes gegen die Gewohnheitsverbrecher im Laufe der deutschen Strafrechtsrefrom, Würzburg, Mayr, 1935, p. 65.

${ }_{66}$ J. D. JANSING, Nachträgliche Sicherungsverwahrung..., op. cit., p. 41.

${ }_{77}$ Sobre la problemática del $\$ 20$ StGB véanse L. SCHÄFER y O. WAGER, Gesetz gegen gefährliche Gewobnheitsverbrecher und über Maßregeln der Sicherung und Besserung, Berlin, Vahlen, 1934, p. 37; K. KeSTEL, Der Gewohnheitsverbrecher nach $\$ 20$ StGB, Emsdetten, H. \& J. Lechte, 1935, p. 11, y G. Meyer, Die Behandlung des Kampfes..., op. cit., p. 71. 
tual peligroso ${ }^{68}$. La introducción del § 20 StGB implicaba, por tanto, la tipificación no de un hecho concreto, sino de una verdadera forma de vida ${ }^{69}$. Esta previsión se completaba con la disposición contenida en el § 42.e) StGB, que introducía la medida de custodia de seguridad ${ }^{70}$. De acuerdo con esta nueva figura, cuando concurrieran los requisitos para la aplicación de la agravación contenida en el § 20.a) StGB el juez sumaría la aplicación de la medida de custodia de seguridad siempre que la seguridad pública así lo exigiese ${ }^{71}$.

${ }^{68}$ Alternativamente podía aplicarse también esta regla cuando el sujeto hubiera sido condenado anteriormente en dos ocasiones por hechos delictivos dolosos, siempre que llevara a cabo un nuevo hecho delictivo, fuera condenado a una pena de prisión y se determinara que se trataba de un delincuente habitual peligroso.

§ 20. ${ }^{a}$ StGB: «(1) [1] Hat jemand, der schon zweimal rechtskräftig verurteilt worden ist, durch eine neue vorsätzliche Tat eine Freibeitsstrafe verwirkt und ergibt die Gesamtwürdigung der Taten, daß er ein gefährlicher Gewohnheitsverbrecher ist, so ist, soweit die neue Tat nicht mit schwererer Strafe bedrobt ist, auf Zuch thaus bis zu fünf Jahren und, wenn die neue Tat auch obne diese Strafschärfung ein Verbrechen wäre, auf Zuch thaus bis zu fünfzebn Jabren zu erkennen.

[2] Die Strafschärfung setzt voraus, daß die beiden früheren Verurteilungen wegen eines Verbrechens oder vorsätzlichen Vergehens ergangen sind und in jeder von ibnen auf Todesstrafe, Zuchthaus oder Gefängnis von mindestens sechs Monaten erkannt worden ist.

(2) Hat jemand mindestens drei vorsätzliche Taten begangen und ergibt die Gesamtwürdigung der Taten, daß er ein gefährlicher Gewohnheitsverbrecher ist, so kann das Gericht bei jeder abzuurteilenden Einzeltat die Strafe ebenso verschärfen, auch wenn die übrigen im Abs. 1 genannten Voraussetzungen nicht erfüllt sind.

(3) [1] Eine frühere Verurteilung kommt nicht in Betracht, wenn zwischen dem Eintritt ibrer Rechtskraft und der folgenden Tat mehr als fünf Jahre verstrichen sind. [2] Eine frühere Tat, die noch nicht rechtskräftig abgeurteilt ist, kommt nicht in Betracht, wenn zwischen ibr und der folgenden Tat mehr als fünf Jahre verstrichen sind. [3] In die Frist wird die Zeit nicht eingerechnet, in der der Täter eine Freiheitsstrafe verbüßt oder auf behördliche Anordnung in einer Anstalt verwabrt wird.

(4) Eine ausländische Verurteilung steht einer inländischen gleich, wenn die geabndete Tat auch nach deutschem Recht ein Verbrechen oder vorsätzliches Vergehen wäre».

${ }^{69}$ En contra, Topp sostenía que el $\$ 20$ StGB era un precepto que ofrecía la posibilidad de agravar la pena en virtud de la peligrosidad del delincuente, pero que, en todo caso, requería la comisión de otro hecho delictivo. Cfr. E. Topp, Zusammenstellung und Analyse der Rechtsprechung über das Gewohnheitsverbrechergesetz, Hamburg, Preilipper, 1939, p. 17. También al respecto se pronunció Bewerunge, quien al analizar el precepto se planteaba: «¿Contra quién se dirige la amenaza del $\$ 20 \mathrm{StGB}$, contra el hecho o contra el autor?», para llegar posteriormente a la conclusión de que a partir de esta norma no era posible hallar una clara diferencia entre la culpa y la peligrosidad del autor. Cfr. H. BEWERUNGE, Das Gewohnheitsverbrechen (Untersuchung über die Rechsnatur gewohnheitsverbreicherischer Gefährlichkeit), Düsseldorf, G. H. Nolte, 1937, p. 24. En el mismo sentido se pronuncia Henkel, quien señala que este precepto no deja claro si la agravación prevista en el $\S 20$ se justifica en una culpabilidad mayor o si se trata de una causa de agravación objetiva. Cfr. H. Henkel, «Das Sicherungsverfahren gegen Gemeingefährliche (Fortsetzung)», ZStW, núm. 58, 1939, p. 177.

70 \$ 42.e) StGB (1 de enero de 1934-1 de abril de 1970): «Wird jemand nach \$20a als ein gefährlicher Gewobnheitsverbrecher verurteilt, so ordnet das Gericht neben der Strafe die Sicherungsverwahrung an, wenn die öffentliche Sicherbeit es erfordert».

${ }_{71}$ También sumamente controvertido fue el § 51 II StGB, que permitía castigar al delin- 
Se trataba de decisiones directamente encaminadas a cumplir uno de los principales objetivos marcados por un importante sector de la doctrina penal: tomar las medidas eugenésicas necesarias para extirpar los troncos criminales de la sociedad. Según ha manifestado Mezger, las reformas que se habían pretendido emprender hasta el momento habrían resultado ineficaces en caso de haber sido finalmente aprobadas, ya que detrás de la escuela sociológica — que había determinado en mayor medida los lineamientos de la reforma - persistía la idea de que el delito es principalmente un resultado de la responsabilidad de la sociedad en su conjunto, lo que habría hecho decaer las energías internas de la Administración de Justicia $^{72}$. Esta situación, sin embargo, había cambiado totalmente con la asunción del régimen nacionalsocialista, ya que, según el autor alemán, la nueva estructura del Estado contaba con las fuerzas necesarias para defender los dos pilares sobre los que descansaba el Estado alemán: el pueblo y la raza. Para lograr esta máxima aspiración sería necesario cumplir con un doble objetivo: el restablecimiento de la responsabilidad del individuo frente a la comunidad del pueblo, que descansa sobre el dogma del acto y que se consigue mediante la aplicación de penas, y, en segundo término, la eliminación de las partes integrantes nocivas al pueblo y a la raza, que descansa sobre el dogma del autor y para lo cual resultarán imprescindibles las medidas de aseguramiento ${ }^{73}$.

Puede sostenerse, por tanto, que, recogiendo los planteamientos de la doctrina contemporánea mayoritaria, la Ley de 1933 procede a construir la agravante de reincidencia y la medida de custodia de seguridad sobre la base de verdaderos tipos criminológicos de autor. Así, el requisito sustancial sobre el que recaía la aplicación de estas normas exigía la valoración de la totalidad de la personalidad del individuo. Según las palabras de Mezger, esta nueva ley «deduce de las experiencias de la criminología contemporánea las consecuencias prácticas para la administración de la justicia penal» ${ }^{74}$.

En referencia a la interpretación del concepto de «delincuente habitual peligroso», en opinión de Exner, se trataba del delincuente de estado repetidamente reincidente, cuya tendencia a la comisión de delitos graves no podía ser eliminada mediante la aplicación de penas y medidas

cuente semiimputable con la misma pena que al plenamente imputable si se trataba de un delincuente habitual peligroso en los términos del § 20 StGB.

72 E. Mezger, Criminología..., op. cit., p. 282.

73 Ibid., p. 284.

${ }^{74}$ Ibid., p. 283. 
de seguridad. De esta forma, el contenido del término se correspondía con el delincuente incorregible, pero sólo con aquel del cual podía preverse la comisión de hechos de significativa gravedad y no con el delincuente de estado considerado «gravoso», que sólo llevaba a cabo hechos delictivos de menor entidad ${ }^{75}$.

Esta situación, que por sí misma dejaba al arbitrio judicial un gran margen de decisión, se agravaba por el total abandono del principio de legalidad y la decidida aceptación de la analogía im malam partem. Correspondía, por tanto, de acuerdo con el expreso deseo del legislador, que el juez decidiera si, conforme al sano sentir del pueblo, el sujeto resultaba peligroso para la comunidad, con lo que, en la práctica, esta circunstancia terminó aplicándose frente a la mera reiteración de hechos delictivos, aunque, en realidad, la reincidencia era solamente uno de los indicios necesarios para la aplicación de las medidas ${ }^{76}$. Puede afirmarse, por tanto, que las teorías desarrolladas por la doctrina sobre los tipos criminológicos de autor facilitaron al régimen nacionalsocialista el marco de referencia para establecer cláusulas generales relacionadas con la actitud de la persona que le permitieran atarlo a una pena o medida más allá de la responsabilidad por el hecho ${ }^{77}$. Así, se entendía que el hecho es sólo la causa de conocimiento de la peligrosidad del autor, mientras que la peligrosidad es la causa real del hecho. Incluso, durante el trascurso del régimen se acentuó cada vez más la creencia de que el concepto de delincuente habitual no estaba arraigado a los hechos, sino a la personalidad del autor y a su constitución biológica ${ }^{78}$.

${ }^{75}$ F. EXNER, Biología criminal..., op. cit., p. 353. Sobre el concepto de delincuente habitual peligroso en la Ley de 1933 también véanse W. Scholz, Der Begriff des gefährlichen Gewohnheitsverbrechers nach den Gesetz von 24.11.1933, Dresden, Risse-Verl., 1935, p. 20; L. S. WAGNER, Der gefährliche Verbrecher im deutschen, jugoslavischen und italianischen Strafrecht, Bleicherode, Carl Nieft, 1939, p. 19; H. KrIENER, Die Berücksichtigung kriminalbiologischen Forderungen im geltenden und im kommenden Recht, Würzburg, Memminger, 1936, p. 11; L. Lотz, Der gefährliche Gewohnheitsverbrecher, Leipzig, E. Wiegandt, 1939, p. 7, y H. J. KoestLen, Der Begriff des gefährlichen Gewohnheitsverbrechers..., op. cit., p. 73. Sobre el concepto de delincuente por costumbre en los proyectos anteriores a la Ley de 1933 véase E. vON SCHWEIN, Die Gewohnheitsverbrecher in den strafrechtlichen Entwürfen Deutschland seit 1925 und im italianischen Strafgesetzbuch von 1930, unter besonderer Berücksixbtigung der Verbrecher aus Hang im italienischen Strafgesetzbuch, Erlangen, Windsheimer, 1932, p. 29.

${ }_{76}$ J. D. Jansing, Nachträgliche Sicherungsverwahrung..., op. cit., p. 30. En este sentido indicaba Meyer que el $\S 20$ otorgaba al juez una facultad ilimitada de decisión. Cfr. G. Meyer, Die Behandlung des Kampfes..., op. cit., p. 73.

77 J. D. Jansing, Nachträgliche Sicherungsverwahrung..., op. cit., p. 44.

78 Ibid., p. 45. A favor de una interpretación amplia del concepto de delincuente peligroso habitual en la Ley de 1933 véase H. J. KoEsTLER, Der Begriff des gefährlichen Gewohnheitsverbrechers..., op. cit., p. 73. 
Uno de los principales problemas que tuvo que enfrentar la teoría de los tipos de autor ${ }^{79}$ fue, precisamente, lograr compatibilizar la pena que se imponía como consecuencia de la pertenencia de un determinado tipo de autor en algunos supuestos, con la idea de la pena por la culpabilidad en la que se basaba el Derecho penal en los demás casos. La explicación más influyente sobre estos extremos la dio Edmund Mezger con su «teoría de la culpabilidad por la conducción de vida». Para Mezger, la culpabilidad jurídico-penal no era sólo culpabilidad por el hecho aislado, sino también la total culpabilidad por la conducción de su vida que le ha hecho degenerar ${ }^{80}$. Se

${ }^{79}$ Junto a los llamados «tipos criminológicos de autor» la doctrina elaboró el concepto de «tipos normativos de autor». La diferencia entre ambas clasificaciones se centra en el hecho de que, mientras en los tipos criminológicos lo que cuenta es la personalidad total del individuo, la cual debe concordar con las características del tipo de autor específico, en el caso de los tipos normativos es un hecho concreto el que se debe ajustar a la representación que se hace el intérprete del modo de actuar de un actor típico, lo que necesariamente supone llevar a cabo un juicio de valor. La teoría de Dahm defiende el recurso a los tipos normativos de autor. Dahm abogaba por el establecimiento de baremos o módulos valorativos, es decir, imágenes conceptuales o modelos de autor típico que permitirían medir el hecho. De esta forma, sólo si el hecho se ajustaba al baremo, la conducta sería subsumida en el tipo. A modo de ejemplo indicaba Dahm que no puede castigarse a un médico por un aborto con el que este sujeto pretendió salvar la vida de la madre, aun cuando lo realizara sin el consentimiento de la misma, ya que la representación del abortista que existe en la conciencia popular no se adecúa con este caso. Se trataba, por tanto, de que el hecho concreto se ajustara a la representación que se hacía el intérprete del modo de actuar de un autor típico y, por ello, puede sostenerse que esta teoría representaba un método especial de interpretación de los tipos legales en el marco del Derecho penal de autor. Véanse C. Roxin, Derecho Penal. Parte General, t. I, trad. de la 2. ${ }^{a}$ ed. alemana y notas por D.-M. Luzón Peña, M. Díaz y García Conlledo y J. de Vicente Remesal, Madrid, Civitas, 1999, p. 183, y H. Welzel, «Persönlichkeit und Schuld», ZStW, núm. 60, 1941, p. 461 [ver cita 61.a)]. También Edmund Mezger mantiene una teoría de «tipos normativos de autor». Así, el autor alemán en su obra Die Straftat als Ganzes (El Derecho penal como un todo), de 1938, sostiene que el contenido nuclear del delito, entendido como un «todo», está compuesto por el autor y su comportamiento. Delito será, por tanto, un determinado comportamiento de autor. Mezger aceptó que el Derecho penal alemán de su época fue un Derecho penal del hecho y que así debería seguir siendo; no obstante, también consideró que no era posible continuar manteniendo, sin más, la clásica relación hecho-culpabilidad-pena, sino que, de acuerdo con la nueva regulación, la pena «algo tenía que ver con la esencia misma del autor y no solamente con el hecho aislado». El desarrollo de estas ideas le lleva a sostener que, para comprobar la realización de un hecho delictivo, no sólo habrá que preguntarse si un determinado comportamiento puede ser subsumido en un determinado «tipo de hecho delictivo», sino que será necesario comprobar, además, si el comportamiento se adecúa al propio del «autor típico» de ese delito. Véanse E. MezGer, «Die Straftat als Ganzes», ZStW, núm. 57, 1938, p. 675; íD., «Tatstrafe und Täterstrafe im Kriegsstrafrechts», ZStW, núm. 60, 1941, p. 353, y G. Thulfaut, «Continuidad en la dogmática del Derecho penal. ¿Un problema personal? La carrera de Edmund Mezger», Revista General de Derecho Penal, núm. 2, noviembre de 2004, Madrid, p. 6.

${ }^{80}$ E. Mezger, «Die Straftat al Ganzes», op. cit., p. 688. Mezger también recurrió a la teoría de la culpabilidad por la conducción de vida para solucionar los casos que denominó de «ceguera jurídica» y que más tarde prefirió llamar «estados de enemistad jurídi- 
trataba de una forma de culpabilidad que abarcaba, por tanto, toda la personalidad del autor. De esta manera, en el caso del § 20 StGB, la pena no surgía del desvalor del hecho individual, sino de la personalidad caracterológica del autor ${ }^{81}$.

Esta teoría recibió numerosas críticas, incluso durante el periodo nacionalsocialista ${ }^{82}$. Una de las principales objeciones que se le plantearon en el momento de su formulación fue la imposibilidad fáctica de separar culpabilidad y destino, es decir, la dificultad de diferenciar entre las decisiones erradas del sujeto de aquellos estados en los que pudiera caer por las inevitables circunstancias de la vida. Esta objeción llevó a otros autores a sugerir correcciones a la teoría del jurista alemán. En el caso de Bockelmann, el autor sostiene su posición en relación con «la culpabilidad por la decisión sobre la vida», entendiendo que sólo se puede responsabilizar al sujeto por aquello que es resultado de una decisión propia, por lo que, para este autor, la culpabilidad presuponía una decisión del sujeto ${ }^{83}$. Con ello, Bockelmann pretendía abarcar tanto la repentina como la lenta corrupción de la actitud interna, es decir, tanto la adquisición de una posición vital equivocada, como la no superación de una tendencia congénita a la asociabilidad ${ }^{84}$. Por otro lado, Engisch mantiene la relevancia de la marca del destino en el desarrollo de la personalidad del

ca». Se trataba de supuestos en los que el autor, por despreocupación o desprecio hacia el ordenamiento jurídico, ni siquiera se planteaba el carácter prohibido de su comportamiento (error de prohibición evitable). En estos casos, según la teoría de Mezger, no se daba la actualidad del conocimiento requerido para imputar lo realizado a título de dolo y, a pesar de ello, en su opinión, debía castigarse a este sujeto con la pena del delito doloso. En este contexto, la teoría de la «culpabilidad por la conducción de vida» permitió considerar al sujeto culpable aun cuando no hubiera actuado de forma dolosa, basándose en la «actitud» que el autor ha mantenido en el trascurso de su vida pasada en relación con el Derecho. Cfr. E. Mezger, Modernas orientaciones de la dogmática jurídico-penal, trad. de F. Muñoz Conde, Valencia, Tirant lo Blanch, 2000, pp. 67 y ss. Muñoz Conde tilda esta teoría de «inconsecuencia jurídica», ya que en realidad se llegaba a la misma conclusión que con la teoría finalista de Welzel. Cfr. F. MuÑoz Conde, Edmund Mezger y el Derecho Penal de su tiempo. Estudios sobre el Derecho Penal en el nacionalsocialismo, 4. ${ }^{a}$ ed., Valencia, Tirant lo Blanch, 2003, p. 135.

${ }^{81}$ R. Maurach y H. Zipf, Derecho Penal. Parte General, vol. 1, trad. de la 7. a ed. alemana por J. Bofill Genzsch y E. Aimone Gibsen, Buenos Aires, Astrea, 1994, p. 587.

82 Maurach y Zipf señalan que las teorías de la culpabilidad por la conducción de vida no tuvieron éxito ni siquiera mientras el $\S 20$ StGB estaba vigente, ya que una importante parte de la doctrina siguió defendiendo el Derecho penal del hecho. Cfr. R. MAURACH y H. ZIPF, Derecho Penal..., op. cit., p. 587.

83 Véase V. Gómez Martín, El Derecho Penal de Autor..., op. cit., p. 245.

${ }^{84}$ Véanse C. Roxin, Derecho Penal..., op. cit., p. 181, y H. Welzel, «Persönlichkeit und Schuld», ZStW, núm. 60, 1941, p. 462. 
criminal y resalta, además, la responsabilidad por los rasgos no reprochables de la personalidad del individuo ${ }^{85}$.

A pesar del avasallamiento de los derechos individuales que estas decisiones legislativas implicaron, las medidas adoptadas mediante la Ley contra los delincuentes habituales peligrosos no fueron consideradas suficientes para solucionar el problema de los «enemigos internos» del régimen, razón por la cual se preparó el denominado Proyecto de Ley sobre el tratamiento de los «extraños a la comunidad»(Gemeinschaftsfremde). Se trataba de una norma que pretendía introducir medidas específicas de castración y esterilización, además del internamiento en campos de concentración de los que consideraban sujetos «extraños a la comunidad». Este concepto iba mucho más lejos del alcance que podía darse al concepto de delincuente habitual peligroso utilizado en la Ley de 1933 y podía abarcar, entre otros, a vagos, homosexuales, asociales y fracasados.

Tanto Franz Exner como Edmund Mezger asesoraron al gobierno nacionalsocialista para la redacción de este proyecto. Según consta en la correspondencia que Mezger intercambiara con el ministro de Justicia Rietzsch, el afamado autor aconsejaba la utilización del Proyecto de Ley sobre el tratamiento de los extraños a la comunidad para ampliar los términos del § 20 StGB y conseguir que el precepto resultara aplicable no sólo para el delincuente habitual, sino también para el delincuente «por tendencia». En palabras de Mezger, se trataba de «anticipar la línea de defensa» ${ }^{86}$. Mezger en su carta incluía una clasificación de «tipos criminológicos de autor», entre los que puede observarse una línea gradual ascendente. De acuerdo con esta construcción se distinguían:

a) el delincuente «por tendencia»: será el que tiene una disposición para caer en un estado criminal;

b) el «delincuente habitual»: aquí de la tendencia ha surgido un hábito;

c) el «delincuente de estado»: aquí de la tendencia, del hábito, ha surgido un estado criminal, esto es, la última y más grave forma de la evolución criminal ${ }^{87}$.

${ }^{85}$ K. EnGISCH, «Zur Idee der Täterschuld», ZStW, núm. 61, 1942, p. 166, e ÍD., «Bietet die Entwicklung der dogmatischen Strafrechts-wissenschaft seit 1930 Veranlassung, in der Reform des Allgemeinen Teils des Strafrechts neue Wege zu gehen?», ZStW, núm. 66, 1954, p. 339.

${ }_{86}$ F. Muñoz Conde, Edmund Mezger y el Derecho Penal de su tiempo..., op. cit., p. 238, e ÍD., «La esterilización de los asociales en el nacionalsocialismo. ¿Un paso para la solución final de la cuestión social?», Revista Penal, núm. 10, 2002, p. 3.

87 Mezger completa su clasificación con los siguientes tipos criminológicos de autor: 
De esta forma, se sugiere la conveniencia de tomar medidas aun antes de que se manifieste la reiteración de hechos delictivos, es decir, antes de que surja el hábito criminal, imponiendo, por tanto, la custodia cuando se manifieste una mera «disposición» al delito. En este sentido, Mezger reconocerá que, según su clasificación, la característica principal del delincuente por tendencia es psicológica, esto es, la actitud hostil a la comunidad o inclinación al delito, y asumiendo de antemano la dificultad probatoria de una circunstancia de estas características, sugerirá la conveniencia de incluir en la ley algunas pautas objetivas que le indiquen al juez distintos indicios a tener en cuenta para la determinación de la tendencia, como, por ejemplo, la constatación de delitos anteriores ${ }^{88}$. Hay que advertir, no obstante, que después de un largo proceso de gestación, esta ley no llegaría a entrar en vigor debido a la finalización de la guerra.

Suele argumentarse en contra de la medida de custodia de seguridad que se trata de una institución que proviene de la lógica del pensamiento nacionalsocialista ${ }^{89}$. Esta afirmación es sólo correcta de forma parcial. Como se ha indicado, la asunción de las medidas de seguridad, y entre ellas de la custodia, fue un resultado neutral de la guerra de escuelas. Puede sostenerse que, ideológicamente, la custodia responde a los planteamientos de Von Liszt, quien asumiendo una prevención especial exacerbada proponía la reclusión por tiempo indeterminado de los delincuentes incorregibles. Esta circunstancia impediría, por tanto, deslegitimar a la institución de la custodia basándonos únicamente en su origen. No obstante, sí es cierto que el nacionalsocialismo, persiguiendo el objetivo de acabar con el enemigo interno, fue mucho más allá de los planteamientos originales de la figura ${ }^{90}$. El régimen utilizó esta institución y la construcción teórica de los tipos criminológicos de autor para identificar a personas perfectamente imputables como sujetos enfermos, esto es, como a «tipos de hombre peligroso», cuando, incluso, su peligrosidad no se había expresa-

a) «delincuente por conflicto», el que se convierte en criminal por una situación extraordinaria de conflicto interno; b) «delincuente ocasional», el que delinque llevado por las circunstancias usuales, y $c$ ) «delincuente por inclinación», el que tiene una inclinación a delinquir en general o a cometer determinados delitos. Véase F. MuÑoz CONDE, Edmund Mezger y el Derecho Penal de su tiempo..., op. cit., p. 238.

${ }^{88}$ Ibid., p. 238.

${ }^{89} \mathrm{Al}$ respecto véase D. Rössner y D. Best, en D. Dölling, G. Duttge y D. Rössner (eds.), Gesamtes Strafrecht. StGB/StPO/Nebengesetze, 2." ed., Baden-Baden, Nomos, 2011, p. 607 .

${ }^{90}$ En este sentido, R. Rissing-Van SaAn y J. Peglau, Strafgesetzbuch. Leipziger Kommentar, Berlin, W. de Gruyter, 1957-1958, p. 412. 
do a través de la realización de hechos concretos, sino a través de su modo de vida o su supuesta actitud de enemistad con el pueblo ${ }^{91}$. Así, el pensamiento positivista fue llevado al extremo por el nacionalsocialismo, persiguiendo objetivos de sobra conocidos y que no es necesario referir, lo cual demuestra perfectamente la peligrosidad de este tipo de teorías que, como toda arma potencialmente lesiva, en caso de caer en las manos equivocadas puede producir resultados catastróficos.

\section{Las medidas de seguridad durante la época de posguerra}

A pesar de su carácter sumamente controvertido, tanto la agravante contenida en el $\S 20 \mathrm{StGB}$, como la medida de custodia de seguridad incluida en el § 42.e) StGB se mantienen prácticamente inalteradas hasta el año 1970. Sobrevivirán, por tanto, a la reforma operada en el Código Penal en el año 1953, y será con la denominada Primera Ley de Reforma (1. StrRg) de 25 de junio de 1969 cuando se produzca una modificación sustancial de sus términos.

Por entonces se decidirá la derogación de la cláusula contenida en el § 20 StGB. Las causas que motivaron esta modificación se basaron en el hecho de tratarse de una disposición incompatible con el Derecho penal de la culpabilidad. Una vez rechazada la validez de la teoría de la culpabilidad por la conducción de vida, la doctrina llegó a la conclusión de que el aumento de pena que el § 20 StGB establecía no era compatible con un sistema que respetara escrupulosamente a la culpabilidad por el hecho como límite de la intervención penal ${ }^{92}$. Posteriormente se mantuvo la agravante de reincidencia, ya despojada de las referencias al carácter y forma de vida del sujeto, hasta su definitiva derogación en el año $1986^{93}$. No obstante, una de las decisiones fundamentales que el legislador de 1969 tuvo que adoptar fue el mantenimiento o no de la medida de custodia de seguridad. Como es sabido, el legislador alemán, a pesar de la existencia de fuertes objeciones al respecto, se decantó por

${ }_{91}$ J. D. Jansing, Nachträgliche Sicherungsverwahrung..., op. cit., p. 48.

92 S. BENDER, Die nachträgliche Sicherungsverwahrung, Frankfurt am Main, Lang, 2007 , p. 23. En el mismo sentido, M. KöGLER, Die zeitliche Umbestimmbeit freiheitsentziebender Santktionen des Strafrechts. Eine vergleichende Untersuchung zur Rechtslage und Strafvollstreckungspraxis in der Bundesrepublik Deutschaland und den USA, Frankfurt am Main, Lang, 1988, p. 69.

93 Sobre la posible inconstitucional de la agravante de reincidencia, R. RISSING-VAN SAAN y J. Peglau, Strafgesetzbuch. Leipziger Kommentar..., op. cit., p. 410. 
la primera opción. Así, el argumento, difícilmente rebatible, sobre la existencia de un «fraude de etiquetas» generó notables reticencias sobre el mantenimiento de un sistema de doble vía. Fueron, finalmente, la necesidad de dar una respuesta al problema del delincuente habitual peligroso y la dificultad del sistema monista de fundamentar la pena indeterminada con base en la culpabilidad las principales razones que motivaron la decisión de proseguir con la dualidad penas-medidas y mantener, por tanto, la vigencia de la custodia de seguridad ${ }^{94}$.

No obstante, la primera ley de reforma procederá a una revisión exhaustiva de los términos en los que se regulaba la medida de custodia de seguridad. Esta modificación seguirá en sus aspectos fundamentales los lineamientos del proyecto alternativo ${ }^{95}$ presentado en 1966 por un grupo de profesores de Derecho penal como contrapropuesta al Proyecto de $1962^{96}$. El texto de 1966, haciendo gala de una pretendida «vuelta a Von Liszt» ${ }^{97}$, antepuso, en todo caso, los objetivos de la resocialización del individuo y, consecuentemente, hizo especial hincapié en la necesidad de que la custodia de seguridad gozara efectivamente del carácter de ultima ratio ${ }^{98}$. Aunque el texto de 1969 no respetará todos los extremos propuestos por el proyecto alternativo, sí se afanará en la tarea de intensificar el carácter preventivo de las medidas y en acotar el marco de aplicación de la custodia de seguridad para que sólo pudiera ser utilizada en supuestos verdaderamente incontrovertibles ${ }^{99}$. Para lograr este objetivo, el legislador aumentó notablemente tanto los requisitos materiales como los de carác-

${ }_{94}$ J. D. JAnsing, Nachträgliche Sicherungsverwahrung..., op. cit., p. 51. Sobre esta problemática también véanse E. DREHER, «Die Vereinheitlichung von Strafen und sichernden Maßregeln», ZStW, núm. 65, 1953, p. 481, y H. DüNNEBIER, «Die Durchführung der Zweispurigkeit bei den freiheitsentziehenden Maßregeln im Entwurf 1960 eines Strafgesetzbuchs», ZStW, núm. 72, 1960, p. 32.

${ }_{95} \mathrm{Al}$ respecto véase $\mathrm{H}$. H. JEsCHECK, «Die krimmalpolitische Konzeption des Alternativ-Entwurfs eines Strafgesetzbuchs (Allgemeiner Teil)», ZStW, núm. 80, 1968, p. 54.

${ }^{6}$ Sobre los trabajos legislativos previos véanse E. DREHER, «Die erste Arbeitstagung der Großen Strafrechtskommssion», ZStW, núm. 66, 1954, p. 568; H. J. BRuNS, «Die Maßregeln der Besserung und Sicherung im StGB-Entwurf 1956», ZStW, núm. 71, 1959, p. 210, y P. NolL, «Diskussionsvotum an der Strafrechtslehrertagung vo. 21. bis 23. Mai 1964 in Hamburg», ZStW, núm. 76, 1964, p. 707.

${ }_{97}$ C. RoxIN, «Franz von Liszt undi die kriminalpolitische Konzeption des Alternativentwurfs», ZStW, núm. 81, 1969, p. 613. También véase P. BocKelMANN, «Franz von Liszt und die kriminalpolitische Konzeption des allgemeinen Teils», ZStW, núm. 8, 1969, p. 597.

${ }^{98}$ K. Höffen y J. Kaspar, «Warum das Abstandsgebot die Probleme...», op. cit., p. 87.

${ }^{9}$ H. Sсhӧch, en H. Satzger, B. Y. Schmitt, y G. Widmaier (eds.), StGB. Strafgesetzbuch Kommentar (Introducción al $\$ 66$ ), 1. a ed., Köln, C. Heymanns, 2009, p. 547. También al respecto, R. Rissing-Van SaAn y J. Peglau, Strafgesetzbuch. Leipziger Kommentar..., op. cit., p. 414. 
ter formal. Se trataba de conseguir que la medida sólo resultase aplicable frente a los delincuentes especialmente peligrosos y no frente a la pequeña criminalidad $^{100}$. La Segunda Ley de Reforma del Código Penal, incorporada en 1975, trasladará la medida de custodia de seguridad al § 66 StGB sin realizar modificaciones de contenido.

El mantenimiento de la custodia de seguridad en el Código Penal durante el periodo de la posguerra y su nuevo planteamiento por parte de la Primera Ley de Reforma del Código Penal no incentivaron la utilización de esta medida; durante este tiempo su uso fue sólo excepcional ${ }^{101}$. Posteriormente, en la década de los noventa se produce un nuevo cambio de rumbo de la política criminal, motivado esta vez por la alarma social que causaron varios hechos especialmente violentos ${ }^{102}$. Consecuentemente, se reforma la ley con el objetivo de relajar los requisitos formales exigidos para la aplicación de la medida y posibilitar una prolongación de su duración ${ }^{103}$. Como era de esperar, esta situación provoca una escalada en

100 S. BENDER, Die nachträgliche Sicherungsverwahrung..., op. cit., p. 24. También véase C. Guisasola Lerma, Reincidencia y delincuencia habitual, Valencia, Tirant lo Blanch, 2008, p. 52.

${ }^{101}$ Una relación completa de las estadísticas puede encontrarse en K. A. HaLL, «Sicherungsverwahrung und Sicherungsstrafe», ZStW, núm. 70, 1958, p. 41; J. Kern, Brauchen wir die Sicherungsverwabrung. Zur Problematik des § 66 StGB, Frankfurt am Main, Lang, 1997, p. 16; M. SKRIL, «Die Renaissance der Sicherungsverwahrung - vom Auslaufmodell zur Mode-Maßregel?», Zeitschrift für Strafvollzug und Straffälligenhilfe, 2005, p. 323, y T. BARTSCH, Sicherungsverwahrung..., op. cit., p. 34.

102 Sobre el efecto de los medios de comunicación y el debate sobre la necesidad de una mayor protección de la sociedad, a pesar de que en los mismos años el número de crímenes bajó notablemente, véanse R. REINDL y H. M. WEBER, «Sicherungsverwahrung: Zur Reinaissance eines verdachtsbegründeten Rechtsinstituts», en Jabrbuch für Rechts und Kriminalsoziologie. 25 Jahre Maßnahmenvollzug eine Zwischenbilanz, Baden Baden, Nomos, 2001, p. 137, у A. Boetтicher, «Aktuelle Entwicklungen im Maßregelvollzug und bei der Sicherungsverwahrung - Ambulante Nachsorge für Sexualsträftäter ist Aufgabe der Justiz», NStZ, 2005, p. 417.

${ }_{103} \mathrm{Al}$ respecto véanse D. BEST, «Das Rückwirkungsverbot nach Art. 103 Abs. 2 GG und die Maßregeln der Besserung und Sicherung (§ 2 Abs. 6 StGB)», ZStW, núm. 114, 2002, p. 88; S. EISENBERG y S. SCHLÜTER, «Extensive Gesetzesauslegung bei Anordnung von Sicherungsverwahrung», NJW, 2001, p. 188; H. HammERSCHLAG, «Das Gesetz zur Bekämpfung von Sexualdelikten und anderen gefährlichen Straftaten», NStZ, 1998, p. 321; J. KINZIG, «Das Gesetz zur Einführung der vorbehaltenen Sicherungsverwahrung», NJW, 2002, p. 3204; T. UlLENBRUCH, «Verschäfung der Sicherungsverwahrung auch rückwirkend polulär, aber verfassungswidrig», NStZ, 1998, p. 326; R. BRANDT, Sicherheit durch nachträgliche Sicherungsverwabrung? Zugleich ein Beitrag zur restriktiven Auslegung ibrer formellen Voraussetzungen, Konstnz, Hartung-Gorre, 2008, p. 3; H. PolläHnE, «Trenwende im Strafrecht? Aktuelle Entwicklungen im Maßregelrecht unter besondere Berücksichtigung der Sicherungsverwahrung», Schleswig Holsteinische Anzeigen. Justizministerialblatt für Schleswig - Holstein für das Jahr 2005, 2005, p. 135; C. GuISASOLA LERMA, Reincidencia y 
la aplicación de la custodia de seguridad que se mantiene hasta nuestros días ${ }^{104}$. Estas modificaciones no afectarán a la redacción de los requisitos materiales, que se mantendrán prácticamente inalterados desde su formulación en 1969.

\section{TENDENCIA Y PELIGROSIDAD. LOS REQUISITOS MATERIALES DE LA MEDIDA DE CUSTODIA DE SEGURIDAD}

De acuerdo con la nueva formulación del § 66.1.4 StGB la medida de custodia de seguridad debe aplicarse cuando:

«De la valoración en conjunto del autor y de sus hechos resulta que como consecuencia de su tendencia a cometer hechos antijurídicos significativos, especialmente aquellos en los que la víctima resulte perjudicada gravemente psíquica o corporalmente o se causen graves perjuicios económicos, en el momento de la sentencia el sujeto es peligroso para la comunidad» $»^{105}$.

Como puede observarse, el legislador cambia la denominación de «delincuente habitual peligroso», incorporada por la Ley de 1933 y mantenida hasta 1969 , por la de «delincuente por tendencia» ${ }^{106}$. Resulta difícil comprender las bondades de esta decisión. Si en el ámbito de los requisitos materiales se pretendía, tal como sucedió en relación con los requisitos formales, aumentar el grado de exigencia para limitar el ámbito de aplicación de la figura, no parece que se haya tomado la decisión más acertada.

delincuencia habitual..., op. cit., p. 52, y E. BORJA JIMÉNEZ, «Custodia de seguridad, peligrosidad poscondena y libertad en el estado democrático de la era de la globalización: una cuestión de límites», Revista General de Derecho Penal, núm. 18, 2012, p. 26.

${ }_{104}$ Así, la regulación de la medida dejará de estar orientada fundamentalmente a la socialización del individuo para poner el acento en la idea de seguridad. Cfr. H. SCHÖCH, en H. Satzger, B. Schmitt y G. Widmaier (eds.), StGB. Strafgesetzbuch Kommentar.., op. cit., p. 547.

${ }^{105}$ «Die Gesamtwürdigung des Täters und seiner Taten ergibt, dass er infolge eines Hanges zu erheblichen Straftaten, namentlich zu solchen, durch welche die Opfer seelisch oder körperlich schwer geschädigt werden, zum Zeitpunkt der Verurteilung für die Allgemeinheit gefährlich ist» (la referencia temporal relativa al momento en que tiene lugar la sentencia condenatoria se introduce mediante la reforma operada al Código Penal en 2011).

${ }_{106} \mathrm{El}$ «autor por tendencia» es el «sucesor legal» del «delincuente habitual». Cfr. H. L. KRÖBER, «Psychiatrische Aspekte der Sicherungsverwahrung», Monatsschrift für Kriminologie und Strafrechtsreform, año 87, 2004, p. 267. En el mismo sentido, R. REINDL y H. M. WEBER, «Sicherungsverwahrung: Zur Reinaissance...», op. cit., p. 141. 
En efecto, en multitud de ocasiones, tanto por parte de la jurisprudencia como de la doctrina, se recurrió al concepto de «tendencia» para dotar de contenido al requisito de la habitualidad criminal ${ }^{107}$. Solía considerarse que delincuente habitual era el delincuente que se encontraba en un «estado» criminal por el que estaba inclinado a cometer reiteradamente hechos delictivos graves. También en la actualidad suele interpretase el concepto de «tendencia» como una «arraigada inclinación que lleva al sujeto a cometer hechos delictivos relevantes», con lo cual la modificación operada en 1969 carece, en este aspecto, de efectos prácticos ${ }^{108}$. Opinión diferente puede merecer la introducción de la expresión «hechos antijurídicos significativos». Esta exigencia incorpora una limitación referida a las posibles conductas criminales futuras que es novedosa en la legislación y que sí puede permitir una mayor restricción de su aplicación ${ }^{109}$.

La escasa entidad de la reforma operada en este ámbito mantendrá la vigencia de gran parte de los problemas interpretativos que generaban los viejos $\S \S 20$ y 42.e), incorporando, además, incertidumbres de nuevo cuño. $\mathrm{Al}$ respecto, el primer interrogante que se plantea se refiere a la naturaleza misma de la expresión «delincuente por tendencia». Así, al igual que sucedía con el «delincuente habitual peligroso», la doctrina se plantea si estamos frente a un «tipo criminológico de autor» o si se trata de un concepto de carácter normativo.

Antes de la reforma de 1969 la doctrina utilizaba distintas denominaciones para referirse al delincuente habitual peligroso. Así, Maurach hacía alusión al «tipo de delincuente habitual» ${ }^{110}$, Hellmer al «tipo de autor

107 E. W. Hanack, Strafgesetzbuch. Leipziger Kommentar.., op. cit., p. 224.

${ }^{108}$ Hanack considera que la diferencia entre el «delincuente habitual» y el «delincuente por tendencia» puede hallarse en el hecho de que la expresión «tendencia» señala que la convicción al crimen no necesita ser el resultado de la costumbre, sino que también puede ser el resultado de una inclinación innata. Cfr. E. W. Hanack, Strafgesetzbuch. Leipziger Kommentar..., op. cit., p. 224. En el mismo sentido véase R. MauraCH, K. H. Gössel y H. ZIPF, Derecho Penal..., op. cit., p. 881.

109 En este sentido, J. HeLLmER, «Hangtäterschaft und Berufsverbrechertum», ZStW, núm. 73, p. 449. Al respecto Böllinger y Pollähne consideran que para evaluar la circunstancia del daño se deberán tener en cuenta dos circunstancias objetivas: la gravedad de los daños que pueden esperarse, que deberá ser considerada de acuerdo con una medida general-objetiva, y el significado que estos daños pueden tener para las presuntas víctimas, donde la medida deberá ser especial-objetiva. Cfr. L. Böllinger y H. Pollähne, en U. KindhaÜSeR, U. Neumann y H. U. PAeffGen (eds.), Strafgesetzbuch. Leipziger Kommentar.., op. cit., p. 2137. Al respecto véase K. KüHL, Strafgesetzbuch Kommentar, 27. " ed., München, Beck, 2011, p. 461.

110 R. Maurach, Deutsches Strafrecht. Allgemeiner Teil, ein Lebrbuch, Karlsruhe, C. F. Müller, 1965, p. 201. 
del delincuente habitual» ${ }^{111}$, e incluso Schröder se refería expresamente al «tipo de autor criminológico» para hablar poco después del concepto de «delincuente habitual» ${ }^{112}$. Con lo cual, una cuestión de suma trascendencia quedaba velada detrás de numerosas inconcreciones. Naucke, en cambio, dedica especial atención a esta problemática. En su detallada exposición, este autor considera que es necesario mantener una clara diferenciación entre el tipo empírico y el concepto normativo, ya que de la misma deberán extraerse sustanciales consecuencias prácticas ${ }^{113}$.

Tal como lo describe este autor, el concepto abstracto es una clase de representación general. Podemos encontrar este tipo de representación cuando se consideran determinadas circunstancias en relación con un objeto. De esta forma, el delincuente habitual peligroso del § 20 sería un concepto si esta expresión definiera exactamente al objeto que representa y permitiera realizar una segura subsunción de los hechos acaecidos en la realidad. Se trataría, por un lado, de un concepto borroso cuando la definición no fuera cerrada y no permitiera realizar una subsunción con un elevado índice de seguridad. Por otro lado, la abstracción del «tipo» tendrá una estructura diferente y será más difícil de determinar. También se tratará de una relación de circunstancias, pero las mismas no se encontrarán aisladas como en el concepto, sino que serán comparadas y utilizadas como instrumento de investigación criminológica. El tipo no tendrá valor de conocimiento exacto, sólo de orden y comparación. Así, el procedimiento para determinar que un hombre pertenece a un tipo sería realizado mediante una comparación ${ }^{114}$.

Consecuentemente, en opinión de Naucke, la expresión «delincuente habitual peligroso» no puede corresponderse con la estructura del tipo empírico. La abstracción del tipo contiene una estructura abierta con contornos poco definidos que se caracteriza por la imposibilidad de su exacta definición y subsunción, por lo cual no es adecuado para dotar de contenido a una regla jurídica. El delincuente habitual será, por tanto, un concepto, y un concepto no aclarado o borroso, porque tanto el término «hábito» como la referencia al «peligro» no se pueden cerrar, por lo que se mantiene en la indefinición la oportunidad de su aplicación a un sujeto determi-

${ }^{111}$ J. Hellmer, «Hangtäterschaft und Berufsverbrechertum», op. cit., p. 441.

112 A. SCHÖNKE y H. SCHRÖEDER, Strafgesetzbuch, 10. ${ }^{a}$ ed., München, Beck, 1961, introducción al § 20.

${ }_{113}$ W. NAUCKE, «Methodenfragen zum Typ des Gewohnheitsverbrechers», en Monatsschrift für Kriminologie und Strafrechtssrefrom, año 45, vol. 3/4, Köln, 1962, p. 84.

${ }^{114}$ Ibid., p. 91. 
nado ${ }^{115}$. A la misma conclusión llegará actualmente la doctrina mayoritaria en relación con el «delincuente por tendencia», dejando atrás su caracterización como un tipo criminológico de autor y aceptando su configuración como un verdadero concepto normativo ${ }^{116}$.

La representación del delincuente habitual como un concepto «borroso» llevará a Hellmer a defender la existencia de una verdadera laguna del Derecho. En opinión de este autor, el legislador ha tenido una muy buena oportunidad de solucionar esta carencia con ocasión de la reforma del Código Penal, la cual fue desaprovechada mediante la inclusión del término «tendencia», que tradicionalmente ha servido para definir el alcance del delincuente habitual y que, por tanto, comparte esta problemática ${ }^{117}$. En este contexto será necesario analizar el desarrollo doctrinal y jurisprudencial de estos conceptos normativos para saber si su interpretación ha logrado solventar la inicial indefinición de sus postulados.

$\mathrm{La}$ «tendencia» al delito ha sido definida por el Tribunal Constitucional como un «hecho psicológico» ${ }^{118}$. También el Bundesgerichtshof se ha referido a esta circunstancia como «una intensa inclinación a la fractura de la ley a casusa de una disposición característica o adquirida a través del ejercicio» ${ }^{119}$. Se trata, por tanto, de un estado interno arraigado del autor que lo lleva, una y otra vez, a cometer hechos delictivos. Un instinto o adicción a estos hechos no será, por otro lado, necesario, bastando con una mera debilidad hacia la

${ }^{115}$ Ibid., p. 96.

${ }^{116}$ En opinión de Hanack, el término «delincuente por tendencia» no implica que el sujeto deba ser la corporización de un tipo criminológico de autor, sino que se trata de un concepto que, visto desde un punto de vista criminológico, puede abarcar distintos tipos de autor. Cfr. E. W. HanACK, Strafgesetzbuch. Leipziger Kommentar.., op. cit., p. 225. Böllinger y Pollähne entienden que se trata de un concepto normativo que contiene la tipología creada por von Liszt. Cfr. L. Böllinger y H. Pollähne, en U. Kindhaüser, U. Neumann y

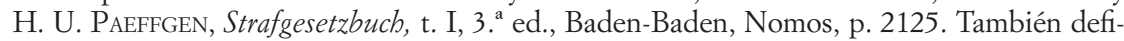
ne al autor por tendencia como un concepto normativo H. SCHÖCH, en H. SATZGER, B. SCHMitT y G. WIDMAIER (eds.), StGB. Strafgesetzbuch Kommentar..., op. cit., p. 579; H. L. KRÖBER, «Psychiatrische Aspekte der Sicherungsverwahrung», op. cit., p. 265, y E. HABERMEYER, P. Hoff y H. SASS, «Das psychiatrische Sachverständigengutachten zur Hangtäterschaft Zumutun oder Herausforderung?», Monatsschrift für Kriminologie und Strafrechtsreform, año 85, 2002, p. 20.

${ }_{117}$ J. HelLmer, «Hangtäterschaft und Berufsverbrechertum», op. cit., p. 445. El autor publica su trabajo en el año 1961 y se refiere a los trabajos previos a la reforma del Código Penal donde ya se manifestaba la intención de sustituir el término «delincuente habitual» por el de «tendencia», lo que, como se ha explicado, implicaba, en opinión del autor, la pérdida de una buena oportunidad de cubrir un importante vacío legal.

118 «Eine psychologische Tatsache», BVerfG, NJW, 06, 3483.

119 «Auf eine charakterlicher Anlage berubende oder durch Übung erworbene intensive Neigung zu Rechtsbrüchen», NStZ, 00, p. 578. 
delincuencia ${ }^{120}$. La comprobación de este estado requerirá, por tanto, de la realización de una valoración de la personalidad del sujeto con base en su comportamiento pasado, donde los hechos anteriores tendrán un carácter sintomático y funcionarán como indicio de una tendencia peligrosa.

La negativa mayoritaria a aceptar que el delincuente por tendencia es un tipo criminológico de autor no implica que la criminología no pueda colaborar en el esclarecimiento de su ámbito de aplicación. Por otro lado, será la experiencia criminológica la que pueda ofrecer la representación más certera de este grupo de delincuentes ${ }^{121}$. Tradicionalmente, la criminología ha propuesto la distinción de los criminales en dos clases de sujetos ${ }^{122}$ :

a) Los delincuentes débiles de carácter son sujetos con una marcada debilidad social que llevan una vida parasitaria. Se trata, por tanto, de individuos muy dependientes de su entorno en los que su comportamiento es un reflejo del ambiente en el que se desenvuelven. Los hechos cometidos suelen ser de distinta clase, entre ellos, hurtos, pequeños robos y lesiones, buscando, en todo caso, satisfacer a través de estos delitos sus necesidades espontáneas.

b) Los delincuentes crónicos activos, por otro lado, no son víctimas de su ambiente, sino que suelen ser quienes arrastran a otros al crimen. Frente a este tipo de individuos los hechos son sólo un síntoma de su voluntad delictiva. Los delitos que cometen son especializados y, en muchos casos, se trata de miembros de bandas delictivas. A diferencia del delincuente por debilidad, el delincuente crónico activo persigue a través de sus crímenes la obtención de ganancias que van más allá de sus necesidades básicas.

Respecto a esta clasificación ha puesto de manifiesto Hellmer que, en contra de lo que hubiera sido deseable, desde su introducción en el Código Penal la custodia de seguridad fue aplicada mayoritariamente al delincuente por debilidad ${ }^{123}$. Así, a pesar de que los hechos que comete este grupo de sujetos suelen ser molestos pero de escasa entidad, también se encuen-

${ }^{120}$ E. W Hanack, Strafgesetzbuch. Leipziger Kommentar..., op. cit., p. 231.

${ }^{121} \mathrm{Al}$ respecto véase H. L. KRÖBER, «Psychiatrische Aspekte der Sicherungsverwahrung», op. cit., p. 265.

$122 \mathrm{Al}$ respecto véase E. W. Hanack, Strafgesetzbuch. Leipziger Kommentar..., op. cit., p. 226

123 J. HellmeR, «Hangtäterschaft und Berufsverbrechertum», op. cit., p. 451. Respecto a esta opinión, aclara Hanack, que a pesar de su opinión, Hellmer reconoce el deber de protección de la comunidad que le asiste al estado en referencia a estos individuos. Cfr. E. W. Hanack, Strafgesetzbuch. Leipziger Kommentar.., op. cit., p. 207. 
tran en una situación de mayor vulnerabilidad, lo que los hace más proclives a ser descubiertos. Por otro lado, los delincuentes activos no son fácilmente identificables, ya que en muchas ocasiones suelen ocultarse bajo la falsa apariencia de buenos ciudadanos. En opinión de este autor, la medida de custodia de seguridad sólo debería ser aplicada al delincuente activo. El delincuente por debilidad es un ser asocial o antisocial para el cual no resulta conveniente ni la aplicación de una agravante ni de la custodia de seguridad. Esta clase de sujetos deberían someterse a medidas que estuvieran destinadas principalmente a su recuperación y sólo en aquellos casos en que existan razones suficientes para pensar que la aplicación de las mismas puede desencadenar un cambio en el estado del individuo. Según Hellmer, el tratamiento del delincuente por debilidad es más efectivo si no se lo aparta de la sociedad, por lo que de ninguna forma puede ser adecuada la aplicación de una medida de las características de la custodia de seguridad ${ }^{124}$. A pesar de su inapelable lógica, esta opinión no es seguida ni por la jurisprudencia ni por la doctrina mayoritaria, que consideran, de forma prácticamente unánime, que esta medida resulta aplicable tanto al delincuente crónico activo como al delincuente por debilidad ${ }^{125}$.

En relación con las causas que pueden originar esa tendencia, resulta indiferente que se trate de una consecuencia del ambiente en el que el sujeto se desenvuelve, del ejercicio de actividades delictivas o bien simplemente de una disposición innata. De acuerdo con la doctrina mayoritaria, lo relevante será la mera existencia de esa inclinación al delito, independientemente de cómo se haya adquirido. Así, podrá tratarse de una disposición psíquica que puede provocar, a su vez, una imputabilidad disminuida. De la misma forma, la tendencia podrá ser también un resultado a la adicción a las drogas o incluso al juego ${ }^{126}$. Tampoco será imprescindible la existencia de una decisión duradera de cometer hechos delictivos ${ }^{127}$. Así, la gran amplitud de circunstancias que pueden quedar abarcadas lleva a que la tendencia, en la práctica, sólo pueda excluirse frente a la realización de actos pasionales o en aquellos casos en los que el delito sea el resultado de factores externos ${ }^{128}$.

124 J. HeLlmER, «Hangtäterschaft und Berufsverbrechertum», op. cit., p. 453.

125 E. W. Hanack, Strafgesetzbuch. Leipziger Kommentar.., op. cit., p. 225, y L. BölLiNger y H. Pollähne, en U. Kindhaüser, U. Neumann y H. U. Paeffgen (eds.), Strafgesetzbuch..., op. cit., p. 2135.

126 Puede deberse también a causas afectivas o a tensiones internas que funcionen como incentivos para no poder resistirse al crimen. Cfr. K. KüHL, Strafgesetzbuch Kommentar..., op. cit., p. 461.

${ }_{127}$ T. Fischer, Strafgesetzbuch und Nebengesetze, 59. ${ }^{a}$ ed., München, Beck, 2012, p. 572.

128 Como conceptos opuestos a la tendencia se habla de hechos por conflicto, oportuni- 
Sumamente relevante será destacar que esa «tendencia» al delito podrá ser culpable o no ${ }^{129}$. Sobre este extremo se ha pronunciado SchülerSpringorum. El autor critica la posibilidad de neutralizar una tendencia «culpable» al delito a través de la aplicación de una medida de seguridad. En su opinión, esta posibilidad choca con las mismas dificultades que llevaron a la derogación del $\S 20 \mathrm{StGB}^{130}$. La aplicación de la custodia de seguridad frente a una tendencia culpable implica un reproche al sujeto no por la realización de un hecho concreto, sino por la forma en que ha desarrollado su vida. Se trataría de una verdadera culpabilidad por la conducción de vida ${ }^{131}$.

En el mismo sentido se ha pronunciado Fischer. Para este autor, la introducción de la citada regla en el año 1933 respondió sólo a una cuestión práctica: el gobierno pretendía evitar que los jueces se negaran a la aplicación de extensas penas cuando los hechos delictivos cometidos no eran de especial gravedad. Con este objetivo se creó la regla que indica que el «hábito» de cometer hechos delictivos no está necesariamente relacionado con la culpabilidad. Así, cuando el legislador de 1969 mantiene la medida de custodia de seguridad en el Código Penal arrastra el déficit de justificación con el que ya contaban las previsiones de la Ley de 1933, incorporando una medida que es incompatible con el criterio de la imputabilidad individual y que toma como válidos los criterios de la neurobiología ${ }^{132}$. Entendemos que a estos autores no les falta razón al realizar estas afirmaciones. Así, a pesar de que las medidas de seguridad no se imponen como un reproche al sujeto, sino sólo como medio de defensa de la sociedad frente a su peligrosidad, lo cierto es que la similitud empírica entre pena y medida lleva a que en la práctica se trate de una agravación velada de la pena. No es posible dejar atrás el hecho de que se trata, en todo caso, de privar al sujeto de su libertad sólo por la forma en que ha decidido

dad o instantáneos (Konflikt, Gelegenheits oder Augenblickstaten). A pesar de ello la realización de hechos en oportunidades aisladas puede llegar a tener valor indicial de la tendencia. $\mathrm{Al}$ respecto véase O. MiLde, Die Entwicklung der Normen zur Anordnung der Sicherungsverwahrung in den Jabren von 1998 bis 2004, Hamburg, Kovac, 2006, p. 63.

${ }^{129}$ K. KüHL, Strafgesetzbuch Kommentar.., op. cit., p. 461. Al respecto, se ha puesto en duda en qué medida es posible diferenciar una tendencia «sana»o «normal» de una patológica. Cfr. E. Habermeyer, P. Hoff y H. SASS, «Das psychiatrische Sachverständigengutachten...», op. cit., p. 20.

${ }^{130}$ H. SCHÜLER-SPRINGORUM, «SV ohne Hang?», Monatsschrift für Kriminologie und Strafrechtsreform, año 79, p. 150.

131 En contra, R. Maunach, K. H. Gössel y H. Zipf, Derecho Penal. Parte General..., op. cit., p. 881.

132 T. Fischer, Strafgesetzbuch und Nebengesetze..., op. cit., p. 565. 
conducir su vida ${ }^{133}$. Además, como sostiene Schüler-Springorum, la mayor culpabilidad del reincidente es una presunción empírica contra reo ${ }^{134}$.

La doctrina también ha prestado especial atención a los factores que resultan decisivos en la determinación de la tendencia, así como al peso que debe tener cada uno de ellos en esta decisión; a pesar de ello, las respuestas que se han obtenido no pasan de ser una mera enumeración sin más valor que el meramente orientativo. Como síntomas de la tendencia suelen destacarse ${ }^{135}$ :

1. El origen del autor, el comportamiento de la familia, la educación que ha recibido y su propio comportamiento durante la juventud.

2. La estructura de la personalidad general del autor, su inteligencia y su carácter; la debilidad del carácter, la falta de sentimientos, valorándose en menor medida las limitaciones del entendimiento.

3. El comportamiento social general del autor, la costumbre de beber, su forma de proceder con la familia, en el trabajo, en su tiempo libre.

4. Su actividad criminal anterior. Al respecto, será de suma importancia la velocidad de la reincidencia, el inicio de la actividad criminal y la forma en que se llevan a cabo los actos criminales. Así, el inicio temprano de la criminalidad es un síntoma importante de la tendencia; por otro lado, el número de delitos cometidos será de menor entidad.

Como puede observarse, se trata de meros indicios que serán presentados al juez en forma de dictamen emitido por un experto y con base en los cuales deberá decidir sobre la existencia de una tendencia criminal ${ }^{136}$.

${ }^{133}$ En este sentido se sostiene que la custodia de seguridad es una pena bajo la forma de una medida. Véase R. REINDL y H. M. WEBER, «Sicherungsverwahrung: Zur Reinaissance...», op. cit., p. 151.

${ }^{134}$ H. SCHÜLER-Springorum, «SV ohne Hang?», op. cit., p. 150. Frente a esta situación el autor propone, o bien limitar el alcance de la tendencia para que sólo queden incluidos casos patológicos, o bien eliminar el concepto de la definición de la custodia de seguridad. En opinión del autor, esta última posibilidad no supondría la extensión de la aplicación de la medida, ya que el término no cumple con la función de limitación tal como sería deseable.

135 Al respecto véase E. W. HANACK, Strafgesetzbuch. Leipziger Kommentar..., op. cit., p. 233. También véase D. Rössner y D. Best, en D. Dölling, G. DutTge y D. Rössner (eds.), Gesamtes Strafrecht, op. cit., p. 625, y J. KERN, Brauchen wir die Sicherungsverwahrung..., op. cit., p. 21.

136 Sobre este particular véase H. Jung, «Die Prognoseentscheidung zwischen rechtlichem Anspruch und kriminologischer Einlösung», en W. Frisch y T. Vogt (eds.), Prognoseentscheidungen in der strafrechtlichen Praxis, Baden-Baden, Nomos, 1994, p. 163, y A. Boetticher, H. L. KröBer, R. Müller-Isberner, K. M. Böhm, R. Müller-Metz y T. Wolf, «Mindestandforderungen für Prognosegutachten», NStZ, 2006, p. 537. 
Los requisitos materiales para la aplicación de la medida de custodia de seguridad se completan con la exigencia referida a la peligrosidad criminal del sujeto. Tal como lo expresa el legislador, de la tendencia a la comisión de hechos delictivos de significativa importancia debe inferirse que el sujeto es peligroso para la comunidad. Esta expresión plantea numerosos interrogantes acerca de cuál es la relación que une a ambos conceptos, así como a la diferencia que se verifica entre ellos. Sobre este extremo es posible encontrar pronunciamientos jurisprudenciales contradictorios. Así, mientras que en muchas sentencias se manejan los conceptos de tendencia y peligrosidad como si de términos sinónimos se tratara, en otros casos se interpreta la tendencia como el estado del que puede inferirse un pronóstico de futura realización de hechos delictivos ${ }^{137}$. Lo cierto es que la ley no da muchos elementos para poder interpretar correctamente estos conceptos. El único factor indiscutible es el hecho de que en todo el articulado en ningún momento el legislador los utiliza indistintamente, lo cual es un indicio claro de la necesidad de profundizar en la separación de sus contenidos. A pesar de ello, el resultado final es que en ocasiones se decide por la tendencia la existencia de peligrosidad y en otros casos por la peligrosidad se llega a la tendencia; tanto la jurisprudencia como la doctrina, por tanto, suelen dejar en la indefinición la diferenciación entre los dos términos ${ }^{138}$.

El problema que se deriva de esta situación es que resulta sumamente sencillo caer en un argumento circular. Así sucedería si de la reiteración de hechos delictivos se infiriera la tendencia y de esa tendencia, a su vez, se diera por probado el pronóstico de peligrosidad futura ${ }^{139}$. Para solventar esta dificultad suele considerarse que la tendencia es un atributo que describe una disposición individual a la comisión de hechos delictivos y que contiene un diagnóstico. Sin embargo, esta prognosis, que es la peligrosidad, no puede apoyarse solamente en el diagnóstico, sino que tienen que ser considerados otros factores externos que pueden influir en el desarrollo interno y, por tanto, relativizar el peso del mentado diagnóstico inicial ${ }^{140}$. No obstante, lo cierto es que la gran confusión teórica de los términos no anima al optimismo acerca de su correcta aplicación.

\footnotetext{
p. 572 .

138 T. Fischer, Strafgesetzbuch und Nebengesetze..., op. cit., p. 573. También véase S. EISENBERG y S. SCHLÜTER, «Extensive Gesetzesauslegung...», op. cit., p. 188.

139 J. KInZIG, «Die Praxis der Sicherungsverwahrung», ZStW, núm. 109, 1997, p. 127. p. 423

${ }_{140}$ R. Rissing-van SaAn y J. Peglau, Strafgesetzbuch. Leipziger Kommentar..., op. cit.,
}

${ }^{137} \mathrm{Al}$ respecto, ampliamente, T. FisCHER, Strafgesetzbuch und Nebengesetze..., op. cit., 
De lo expuesto hasta el momento pueden deducirse varias razones que nos llevan a valorar negativamente la inclusión de la tendencia como requisito material de la medida de custodia de seguridad. El primer punto se refiere, indudablemente, a la inseguridad jurídica que provoca la redacción del § 66.1.4 StGB. Así, la imposibilidad de definir con certeza tanto el concepto de «tendencia» como el de «peligrosidad» ponen en peligro el pretendido carácter de ultima ratio del que supuestamente goza la medida de custodia de seguridad ${ }^{141}$. Al no ser posible determinar de forma fehaciente qué sujetos poseen esa inclinación al delito ni cuáles son los requisitos que deben cumplirse para inferir de la tendencia la peligrosidad, los referidos conceptos pierden la función de límite que deberían garantizar ${ }^{142}$. A esta dificultad se suma el hecho de que los elementos que conforman el concepto de tendencia están sujetos a una comprobación empírica, por lo que no es posible pasar por alto el elevado peligro de que se produzcan falsos positivos $^{143}$. Esta situación provoca que, en la práctica, con demasiada asiduidad, la tendencia sea determinada de forma arbitraria dentro del «relativamente gran grupo» de delincuentes que cumple con los requisitos formales para la aplicación de la medida ${ }^{144}$.

Con el objetivo de respetar el principio de culpabilidad por el hecho, el legislador alemán decidió mantener en el Código Penal un sistema dualista donde la pena funciona como un reproche que responde de forma exclusiva al hecho cometido y donde las medidas de seguridad están destinadas a neutralizar la peligrosidad del sujeto. No obstante, sólo podrá conseguirse que el principio de culpabilidad no pierda vigencia si la aplicación de las medidas de seguridad se encuentra sujeta a unos límites claros y determinados, lo cual no sucede con la redacción actual del § $66^{145}$.

${ }^{141}$ H. Schöch, en H. SAtZger, B. Schmitt y G. Widmaier (eds.), StGB. Strafgesetzbuch Kommentar.., op. cit., p. 574.

${ }_{142}$ T. FIsCHER, Strafgesetzbuch und Nebengesetze..., op. cit., p. 573. En el mismo sentido, H. SCHÜLER-SpringORUM, «SV ohne Hang?», op. cit., p. 154.

${ }_{143}$ Rössner y Best ponen de manifiesto esta situación. A pesar de ello, los autores consideran que la medida no adolece de déficit constitucional, ya que en la práctica resulta factible la comprobación de los resultados psiquiátricos y criminológicos. Cfr. D. RÖssNER y D. Best, en D. Dölling, G. Duttge y D. Rössner (eds.), Gesamtes Strafrecht..., op. cit., p. 624. También véase R. Rissing-van SaAn y J. Peglau, Strafgesetzbuch. Leipziger Kommentar.., op. cit., p. 421.

${ }_{144}$ J. D. Jansing, Nachträgliche Sicherungsverwahrung..., op. cit., p. 77. Kinzig considera que hay pocas decisiones de los tribunales por las que se rechace la aplicación de la custodia de seguridad por no cumplir con el requisito de la tendencia, por lo que el factor decisivo vendrá determinado por la concurrencia de los requisitos formales. Cfr. J. KINZIG, «Die Praxis der Sicherungsverwahrung», op. cit., p. 127.

145 E. W. Hanack, Strafgesetzbuch. Leipziger Kommentar.., op. cit., p. 8. 
Los problemas de seguridad jurídica que plantean estos términos no sólo se deben, sin embargo, a su inconcreción, sino que más grave aún es el hecho de que pueda tratarse de conceptos vacíos de contenido. La tendencia a la realización de hechos delictivos significativos es, según el § 66 StGB, el requisito material central para la aplicación de la custodia de seguridad, de la misma forma que en el caso del $\S 63$ StGB $^{146}$ el estado de inimputabilidad o semiimputabilidad del sujeto será decisivo para la aplicación de una medida de internamiento en un hospital psiquiátrico. Lo mismo sucede en el supuesto del $\S 64 \mathrm{StGB}^{147}$, donde la tendencia a ingerir bebidas alcohólicas será el requisito para el internamiento en un establecimiento de desintoxicación. Así, podría considerarse que se trata de tres circunstancias referidas a la personalidad del sujeto que pueden determinar la aplicación de una medida de seguridad. No obstante, si se analiza con mayor detenimiento será posible comprobar que entre ellas existen diferencias sumamente significativas ${ }^{148}$.

En el caso del § 63 StGB la circunstancia que determina la aplicación de la medida es una enfermedad o un estado patológico del cual se infiere la peligrosidad del sujeto. Por otro lado, el supuesto del § 64 se refiere a una verdadera adicción que permite plantear una prognosis criminal que es llamada «tendencia» por la ley. También en el caso de la custodia de seguridad el Tribunal tiene que probar una suerte de estado que es llamado «tendencia» y que puede fundamentar la peligrosidad del sujeto, si bien en este caso, y a diferencia de los anteriores, el punto de conexión sólo se encuentra en la realización de hechos delictivos ${ }^{149}$. A esta dificultad

146 «\$ 63 Unterbringung in einem psychiatrischen Krankenhaus. Hat jemand eine rechtswidrige Tat im Zustand der Schuldunfäbigkeit (\$20) oder der verminderten Schuldfähigkeit (\$21) begangen, so ordnet das Gericht die Unterbringung in einem psychiatrischen Krankenhaus an, wenn die Gesamtwürdigung des Täters und seiner Tat ergibt, daß von ibm infolge seines Zustandes erbebliche rechtswidrige Taten zu erwarten sind und er deshalb für die Allgemeinheit gefährlich ist».

$147 \ll \$ 64$ Unterbringung in einer Entziebungsanstalt. Hat eine Person den Hang, alkobolische Getränke oder andere berauschende Mittel im Übermaß zu sich zu nebmen, und wird sie wegen einer rechtswidrigen Tat, die sie im Rausch begangen hat oder die auf ibren Hang zurückgebt, verurteilt oder nur deshalb nicht verurteilt, weil ibre Schuldunfäbigkeit erwiesen oder nicht auszuschließen ist, so soll das Gericht die Unterbringung in einer Entziebungsanstalt anordnen, wenn die Gefahr besteht, dass sie infolge ibres Hanges erbebliche rechtswidrige Taten begehen wird. Die Anordnung ergeht nur, wenn eine binreichend konkrete Aussicht besteht, die Person durch die Behandlung in einer Entziehungsanstalt zu beilen oder über eine erhebliche Zeit vor dem Rückfall in den Hang zu bewabren und von der Begebung erbeblicher rechtswidriger Taten abzubalten, die auf ibren Hang zurückgehen».

148 H. SCHÜLER-SPRINGORUM, «SV ohne Hang?», op. cit., p. 147.

149 L. Böllinger y H. Pollähne, en U. Kindhaüser, U. Neumann y H. U. Paeffagen 
se suma el hecho de que en los $\S \S 63$ y 64 el estado o tendencia se encuentra conceptualmente separado de la peligrosidad resultante, mientras que en el $\S 66$, tal como se ha puesto de manifiesto anteriormente, no ha sido posible hasta el momento establecer una diferencia conceptual clara del alcance y diferenciación de estos términos ${ }^{150}$. Estas circunstancias llevan a sostener que en la construcción del § 66 se verifica una sospecha de tautología donde los conceptos no ejercen su función de limitación positiva y sólo son desarrollados de forma negativa ${ }^{151}$.

Frente a esta situación se ha sugerido la conveniencia de reformular los términos de la medida de custodia de seguridad para que sólo resulte aplicable frente a casos en los que la tendencia sea consecuencia de un padecimiento patológico. En este sentido, sostiene Kunz, las medidas contra delincuentes no responsables no resultan problemáticas en un Derecho penal de ciudadanos, ya que estos autores no son capaces de aprovechar la oportunidad de modificación del comportamiento que supone la pena, mientras que la aplicación de este tipo de medidas al delincuente plenamente responsable supone una segunda sanción y una estrategia de exclusión propia del Derecho penal del enemigo ${ }^{152}$.

En el caso del delincuente imputable peligroso se aplica una pena y una medida que sobrepasa el tiempo de la pena con base en un pensamiento de seguridad excluyente. La aplicación de una medida de estas características supone una verdadera incapacitación del sujeto, lo cual lesiona el derecho del culpable a ser tratado como un ser responsable ${ }^{153}$. Así, la estrate-

(eds.), Strafgesetzbuch..., op. cit., p. 2134. En opinión de Kröber, la tendencia del § 64 y el estado del § 63 son analizados como hechos del pasado que deben ser probados en el futuro y a partir de los cuales pueden esperarse hechos antijurídicos. Por otro lado, en el caso del $\S 66$ no se presenta esta dualidad pasado-futuro, ya que son los hechos criminales anteriores los que manifiestan la existencia de una tendencia, lo cual implica, a su vez, una automática evidencia de futuro. A pesar de ello, en opinión de este autor, no puede hablarse de un argumento circular, ya que el factor temporal sólo tiene un sentido. Cfr. H. L. KRÖBER, «Psychiatrische Aspekte der Sicherungsverwahrung», op. cit., p. 265.

${ }^{150}$ H. SchÖch, en H. SatzGer, B. Schmitt y G. Widmaier (eds.), StGB. Strafgesetzbuch Kommentar.., op. cit., p. 578.

${ }^{151}$ H. SChÜLER-SPRingorum, «SV ohne Hang?», op. cit., p. 147, y L. BöLlinger y H. Pollähne, en U. Kindhaüser, U. Neumann y H. U. PaefFgen (eds.), Strafgesetzbuch..., op. cit., p. 2134.

${ }_{152}$ K. L. KunZ, «Die Verwahrung psychisch unauffälliger Straftäter ein problem für den Rechtsstaat? Überlegungen zur Legitimität der sichernden Verwahrung», Schweizerische Zeitschrift für Strafrecht, t. 122, 2004, p. 241.

${ }_{153}$ En este sentido se pronuncia Zaffaroni. El autor considera que el concepto tradicional de peligrosidad es incompatible con la premisa básica del iushumanismo que indica que toda persona está dotada de razón o conciencia. Por ello, si ser persona implica poder proceder a una elección autónoma entre el bien y el mal, y la peligrosidad implica determinación, 
gia excluyente de la custodia de seguridad no trata al individuo como a una persona competente ${ }^{154}$. La incapacitación del delincuente incorregible, que conceptualmente proviene de las propuestas de Von Liszt, es una técnica social de intervención contra los delincuentes propia de un estado totalitario. No en vano, las propuestas del maestro alemán fueron bien recibidas y llevadas hasta sus últimas consecuencias en el Derecho nacionalsocialista. Como ha quedado claro, la figura del delincuente por tendencia no ha logrado superar el fuerte rechazo que generaba el delincuente habitual peligroso por su relación con las investigaciones criminológicas de los años treinta; puede sostenerse, además, que los indicios de tendencia que utiliza hoy en día la jurisprudencia están fuertemente orientados a dichos resultados ${ }^{155}$.

Todo ello nos lleva a sostener que la corriente de pensamiento que fuera iniciada por los autores positivistas de finales del siglo XIX, si bien era irrealizable en sus postulados iniciales, ha originado la idea del delincuente como un ser enfermo, como un ser peligroso, y esta línea de pensamiento, que subsiste hasta nuestros días, pretende justificar la intervención penal sobre hombres responsables más allá de su responsabilidad concreta por el hecho. En la tendencia político-criminal desarrollada a partir de la década de los noventa nuevamente se trata de utilizar el concepto de peligrosidad como arma de defensa de la comunidad frente al delincuente reincidente. En 1932, Flandrack comentaba: «La lucha entre las dos direcciones del Derecho penal ha durado largo tiempo y todavía no ha llegado a su fin» ${ }^{156}$; más de ochenta años después esta afirmación sigue siendo válida, ya que la vieja pugna entre peligrosidad y culpabilidad todavía no ha sido satisfactoriamente resuelta.

\footnotetext{
se llega a la conclusión de que sólo las cosas pueden ser peligrosas, pero no las personas. Siguiendo el razonamiento de este autor, Zaffaroni considera que si por peligrosidad no se entiende «determinación al mal», sino que simplemente se hace alusión a una mera probabilidad de mal, resulta inexplicable que una persona pueda sufrir una pena por una información estadística que, en su caso, puede ser falsa y no cumplirse. Cfr. E. R. ZAFFaroni, A. Alagia y A. Slokar, Derecho Penal. Parte General, México, Porrúa, 2001, p. 52.

${ }^{154}$ K. L. Kunz, «Die Verwahrung psychisch unauffälliger Straftäter...», op. cit., p. 242.

155 E. W. Hanack, Strafgesetzbuch. Leipziger Kommentar.., op. cit., p. 235.

156 «Der Kampf beider Richtungen im Strafrecht hat langue gedauert und ist noch nicht zum Abschluß gekommen». Cfr. F. FLANDRAK, Die persönlichen Sicherungsmittel im Strafrecht und im Strafverfabren, Wien, Manz, 1932, p. 2.
} 


\section{IV. ¿TIENE CABIDA EL CONCEPTO DE DELINCUENTE POR TENDENCIA EN EL DERECHO ESPAÑOL?}

El 11 de octubre de 2012 el Consejo de Ministros aprueba un nuevo Anteproyecto de Ley de Reforma del Código Penal español de 1995. Esta propuesta introduce una modificación sustancial del sistema de medidas de seguridad vigente hasta el momento. Así, se profundiza en la nueva senda iniciada con la reforma del año 2010, que preveía la posibilidad de aplicación de la medida de libertad vigilada para los sujetos imputables, incorporando a nuestra legislación una institución que hasta el momento había resultado ajena al Derecho español: la medida de custodia de seguridad ${ }^{157}$.

157 Anteproyecto de Ley Orgánica por la que se modifica la Ley Orgánica 10/1995, de 23 de noviembre, del Código Penal:

«Se modifica el art. 101, que queda redactado del siguiente modo:

«1. El Juez o Tribunal impondrán, además de la pena que corresponda, la custodia de seguridad del penado cuando se cumplan los siguientes requisitos:

1) Que le haya sido impuesta una pena mínima de tres años impuesta por uno o varios de los siguientes delitos:

a) Delitos contra la vida, la integridad física, la libertad, la libertad o indemnidad sexual.

b) Tráfico de drogas.

c) Delitos cometidos con violencia o intimidación sobre las personas, incluidos los delitos patrimoniales.

d) Delitos contra la comunidad internacional.

e) Delitos de riesgo catastrófico o de incendio.

f) Delitos de terrorismo.

2) Que hubiera sido anteriormente condenado por uno o varios de los delitos a que se refiere el apartado anterior a una pena mínima total de dos años, de la que hubiera extinguido ya en prisión al menos dieciocho meses. A estos efectos se entenderá cumplido en prisión todo el tiempo de cumplimiento efectivo de la pena, aunque lo hubiera sido en régimen abierto.

3) Que exista un pronóstico de comportamiento futuro que revele la probabilidad de comisión futura de alguno de los delitos a que se refiere el 68, punto 1, de este apartado. Este pronóstico será derivado de la valoración conjunta de las circunstancias personales del penado, de los delitos cometidos por él y de las circunstancias concurrentes en los mismos que pongan de manifiesto su tendencia a la comisión de esos delitos.

2. También se impondrá, junto con la pena, la custodia de seguridad cuando el penado lo haya sido a una pena mínima de cinco años de prisión impuesta por la comisión de varios de los delitos a los que se refieren las letras $a$ ), d) of) del número 1 del apartado anterior y se acredite además el cumplimiento del requisito del número 3 del apartado anterior.

3. A los efectos de este artículo, no se computarán las condenas cuando hubieran transcurrido más de cinco años entre su imposición y la comisión del nuevo delito. Dentro de este plazo no se computará el tiempo en que el sujeto hubiera estado cumpliendo una medida privativa de libertad o una pena de prisión, aunque hubiera sido en régimen abierto. 
Esta nueva medida, que según el texto del anteproyecto resultaría aplicable a ciertos delincuentes reincidentes, tendría una duración máxima de diez años y exigiría como requisito material para su aplicación:

«Que exista un pronóstico de comportamiento futuro que revele la probabilidad de comisión futura de alguno de los delitos a que se refiere el punto 1 de este apartado. Este pronóstico será derivado de la valoración conjunta de las circunstancias personales del penado, de los delitos cometidos por él y de las circunstancias concurrentes en los mismos que pongan de manifiesto su tendencia a la comisión de esos delitos».

Como se desprende del texto del articulado, el prelegislador español pretendía introducir en el Código Penal el concepto de «delincuente por tendencia» ignorando deliberadamente los problemas de aplicación práctica y las numerosas críticas que ha protagonizado desde su introducción en la legislación alemana en 1933. No deja de sorprender el hecho de que, mientras la doctrina alemana reclama una completa reforma de la regulación de la custodia de seguridad por la complejidad del sistema y por la inseguridad jurídica que acarrea ${ }^{158}$, el prelegislador español estuviera dispuesto a reproducir en nuestro sistema los mismos problemas que ya han sido puestos de manifiesto en infinidad de ocasiones.

Posteriormente, las duras críticas expresadas por el Consejo del Poder Judicial en su informe al anteproyecto hacen desistir al prelegis-

4. La custodia de seguridad se cumplirá en un establecimiento especial, conforme a un plan individualizado de tratamiento orientado a la reinserción social del sometido a la medida.

También podrá ser cumplida en establecimientos de cumplimiento de penas cuando ello resulte necesario o conveniente para favorecer su reinserción social.

5. A los efectos de este artículo, se valorarán las condenas impuestas por los Tribunales de la Unión Europea, así como las que lo hubieran sido por otros Tribunales en un proceso desarrollado de conformidad con los principios del art. 6 del Convenio Europeo de Derechos Humanos.

6. La custodia de seguridad tendrá una duración de diez años. Transcurrido este plazo, la medida quedará extinguida y se impondrá al sujeto una medida de libertad vigilada con una duración máxima de cinco años».(00)

${ }^{158}$ J. KINZIG y W. STREe, en A. SCHÖNKE y H. SCHRÖDER, Strafgesetzbuch Kommentar, $28 .^{a}$ ed., München, Beck, 2010, p. 984. En el mismo sentido se ha sostenido que, ya que en la práctica el Derecho alemán funciona como un sistema monista, sería deseable su reformulación para que pasara a ser verdaderamente un sistema dualista. Cfr. K. L. KunZ, «Die Verwahrung psychisch unauffälliger Straftäter...», op. cit., p. 251. En el mismo sentido, H. M. WEBER y R. REINDL, «Argumente zur Abschaffung eines umstrittenen Rechtsinstituts», Neue Kriminalpolitik. Forum für Praxis, Politik und Wissenschaft, año 13, núm. 1, febrero de 2001, p. 20. 
lador, al menos de forma momentánea, sobre la incorporación de la custodia de seguridad. De esta manera, el Proyecto de Reforma del Código Penal de 4 de octubre de 2013 mantiene prácticamente intactas las circunstancias agravantes de reincidencia y multirreincidencia, y abandona el propósito de incorporar a la legislación española la controvertida institución. No obstante, el Proyecto sí insiste en su intención de intensificar la utilización de las medidas de seguridad frente al delincuente plenamente imputable, ya que conserva la iniciativa de ampliar la aplicación de la medida de libertad de vigilada. Si bien esta medida no comparte el rigor extremo que implica la continuación de la privación de libertad con posterioridad al cumplimiento de la pena, sí comparte con la custodia de seguridad los mismos fundamentos y el propósito de enmendar al delincuente tendencial.

Esta circunstancia, unida a la pretensión de incorporar también la figura de la prisión indeterminada, no deja lugar a dudas de que el gobierno ha decidido apostar por una prevención especial exacerbada ${ }^{159}$. En este sentido, creemos que, a pesar de que este tipo de medidas estén encaminadas a la resocialización del individuo, no se puede desviar la atención del hecho de que estas reformas suponen la recepción de la vieja figura del delincuente incorregible al que, en todo caso y al precio que sea, es necesario inocuizar ${ }^{160}$.

159 Así, la legislación española se aleja del modelo alabado por la doctrina extranjera por su ausencia de sanciones y medidas indeterminadas. Véase R. REINDL y H. M. WebER, «Sicherungsverwahrung: Zur Reinaissance...», op. cit., p. 161.

160 En este sentido se ha sostenido que, conceptualmente, la custodia de seguridad retrocede a los tiempos de von Liszt y su «delincuente incorregible». Cfr. R. REINDL y H. M. WeBER, «Sicherungsverwahrung: Zur Reinaissance...», op. cit., p. 141. 